Natural Hazards and Earth System Sciences (2002) 2: 91-108

(C) European Geophysical Society 2002

\title{
Short-term climatic impact of the 1991 volcanic eruption of Mt. Pinatubo and effects on atmospheric tracers
}

\author{
G. Pitari and E. Mancini \\ Dipartimento di Fisica, Università de L'Aquila, L'Aquila, Italy
}

Received: 17 April 2001 - Accepted: 19 September 2001

\begin{abstract}
Large explosive volcanic eruptions are capable of injecting considerable amounts of particles and sulphur gases (mostly sulphur dioxide) above the tropopause, causing increases in the stratospheric aerosol optical depth that may be even larger than one order of magnitude. The efolding particle lifetime in the stratosphere is much longer than in the troposphere (one year versus a few days) so that climatic perturbations in a timeframe of a few years are produced after major volcanic eruptions. A climate-chemistry coupled model is used here to study the dynamical effects of the radiative forcing due to stratospheric aerosols formed after the June, 1991 cataclysmic eruption of Mt. Pinatubo in the Philippines. It is shown that the dynamical perturbation is twofold: (a) the stratospheric mean meridional circulation is affected by local aerosol radiative heating (mostly located in the tropical lower stratosphere); (b) the planetary wave propagation in the mid- to high-latitude lower stratosphere is altered as a consequence of decreasing atmospheric stability due to the climatic perturbation. Dynamical results of the climate model are compared with available observations; a discussion is made regarding the similarities with the dynamical regime of the easterly phase of the equatorial quasi-biennial oscillation. Major findings of this study are: (a) radiatively forced changes in the stratospheric circulation during the first two years after the eruption may, to a large extent, explain the observed trend decline of long-lived greenhouse gases $\left(\mathrm{CH}_{4}\right.$ and $\mathrm{N}_{2} \mathrm{O}$, in particular); (b) the dynamical perturbation helps explain why simple photochemical studies of the ozone trends during 1991-1993 generally fail in reproducing the satellite observed feature consisting of a $2 \%$ additional global ozone depletion during 1993 with respect to 1992 . In both cases we conclude that an increase in the mid- to high-latitude downward flux at the tropopause is the key factor for explaining the behaviour of these atmospheric tracers during 1991/92.
\end{abstract}

Correspondence to: G. Pitari (gianni.pitari@aquila.infn.it.)

\section{Introduction}

Background stratospheric sulphate particles are often perturbed by new aerosol formation starting from sulphur dioxide $\left(\mathrm{SO}_{2}\right)$ or hydrogen sulfide $\left(\mathrm{H}_{2} \mathrm{~S}\right)$ injected in situ by volcanic eruptions. In the case of large explosive eruptions, the aerosol optical thickness may increase by more than one order of magnitude. These additional stratospheric particles may play an important role in the chemical budget of the middle atmosphere, producing catastrophic ozone losses (Prather, 1992) and may also add a significant radiative forcing on global climate in a timeframe of a few years (Hansen et al., 1992). The 1991/92 mid-latitude observations collected by Fahey et al. (1993) have clearly shown the effect of the additional Pinatubo aerosols on stratospheric chemistry. A time-dependent model exercise carried out for the WMO (1999) ozone assessment has shown that the photochemical perturbation produced by the Pinatubo aerosols during 1992/93 can roughly explain the magnitude of ozone depletion observed by the Total Ozone Mapping Spectrometer (TOMS) (McPeters et al., 1996), although some timedependent features of the ozone depletion are not correctly captured. Additional radiation scattering and absorption by the volcanic particles may also perturb the ozone distribution through photolysis rates and circulation changes in the stratosphere (Kinne et al., 1992; Pitari and Rizi, 1993; Schoeberl et al., 1993; Kirchner et al., 1999). The historical record of major volcanic eruptions since 1750 is reported in Table 1 (Simkin and Siebert, 1994). $\mathrm{SO}_{2}$ loading is taken from Stoiber et al. (1987), the volcanic explosivity index (VEI) from Simkin and Siebert (1994), the dust veil index (DVI) from Lamb (1970) and Robock and Free (1995), the ice core volcanic index (IVI) from Robock and Free (1995), the mean temperature changes from Angell and Korshover (1985) (Northern Hemisphere, '*') and Jones (1994) ( global, ' + '). The IVI is the average of Northern Hemisphere (NH) and Southern Hemisphere ( $\mathrm{SH})$ values and represents the optical depth at $0.55 \mu \mathrm{m}$. Pinatubo data are from Bluth et al. (1992) $\left(\mathrm{SO}_{2}\right)$ and Stowe et al. (1992) (optical depth). 
Table 1. Major volcanic eruptions of the past 250 years (see text for symbols). VEI $=$ volcanic explosivity index; DVI $=$ dust veil index; IVI = ice core volcanic index; ‘ $*$ ' $=$ Northern Hemisphere; ' + ' = Global

\begin{tabular}{lccccccc}
\hline Volcano & Latitude & Year & VEI & DVI & $\mathrm{SO}_{2}(\mathrm{Tg})$ & IVI & $\Delta \mathrm{T}(\mathrm{K})$ \\
\hline Laki & $64 \mathrm{~N}$ & 1783 & 4 & 2300 & $43-65$ & 0.19 & $-0.14^{*}$ \\
Tambora & $8 \mathrm{~S}$ & 1815 & 7 & 3000 & $34-175$ & 0.50 & $0.18^{*}$ \\
Cosiguina & $13 \mathrm{~N}$ & 1835 & 5 & 4000 & & 0.11 & $-0.32^{*}$ \\
Askja & $65 \mathrm{~N}$ & 1875 & 5 & 1000 & & 0.01 & \\
Krakatau & $6 \mathrm{~S}$ & 1883 & 6 & 1000 & 15 & 0.12 & $-0.25^{*}$ \\
Tarawera & $38 \mathrm{~S}$ & 1886 & 5 & 800 & & 0.04 & \\
SantaMaria & $15 \mathrm{~N}$ & 1902 & 6 & 600 & & 0.05 & $-0.14^{*}$ \\
Ksudach & $52 \mathrm{~N}$ & 1907 & 5 & 500 & & 0.02 & \\
Katmai & $58 \mathrm{~N}$ & 1912 & 6 & 500 & 12 & 0.15 & \\
Agung & $8 \mathrm{~S}$ & 1963 & 4 & 800 & 12 & 0.06 & $-0.31^{*}$ \\
St.Helens & $46 \mathrm{~N}$ & 1980 & 5 & 500 & 2.1 & 0.00 & \\
El Chichón & $17 \mathrm{~N}$ & 1982 & 5 & 800 & $3.3-10$ & 0.06 & $-0.12+$ \\
Pinatubo & $15 \mathrm{~N}$ & 1991 & 6 & 1000 & 20 & 0.13 & $-0.20+$ \\
\hline
\end{tabular}

Angell and Korshover (1985) have calculated the NH surface temperature changes as the difference between the five-year interval immediately after and before the volcanic episodes, with a negative value indicating a cooling after the eruption. The tabulated difference is calculated as the average of 11 stations (New Haven in North America and 10 European stations). Global temperature changes after 1980 are obtained from detrended data (Jones, 1994; IPCC, 1999) averaged over a four-year period after and before the eruptions. A possible explanation for the Tambora data is suggested by Angell and Korshover (1985): a hemispheric temperature recovery following a decadal minimum at the time of the eruption could have masked the volcanic cooling. Rampino and Self (1984) have defined the NH change as the difference between the lowest mean annual temperature in the three years following the eruption and the mean temperature in the year immediately before the eruption. In this case the hemispheric $\Delta \mathrm{T}$ after Tambora is found to range between -0.4 and $-0.7 \mathrm{~K}$.

In this work a model study of the climatic impact of the 1991 eruption of Mt. Pinatubo is presented, with emphasis on the related short-term anomalies produced on the largescale atmospheric circulation. The numerical model adopted here is a climate-chemistry coupled model (CCM), with online interactive aerosol microphysics. The latter is treated in a mass-converving numerical module including gas-particle interactions, with explicit prediction of the aerosol size distribution. The major goal of this study is to show that radiatively forced changes in the stratospheric circulation during the first two years after the eruption may, to a large extent, explain the observed behaviour of long-lived atmospheric tracers $\left(\mathrm{CH}_{4}\right.$ and $\mathrm{N}_{2} \mathrm{O}$, in particular) and may also help explain why simple photochemical studies of the ozone trends during 1991-1993 generally fail in reproducing some timedependent features resulting from satellite measurements (in particular, the 1993 additional $\mathrm{O}_{3}$ depletion with respect to 1992). The paper is organized with: (1) a preliminary survey of stratospheric volcanic aerosols, summarizing the most relevant published results on the Pinatubo impact over the atmosphere; (2) a short presentation of the main model features; (3) a discussion of the most relevant model results on climate forcing and dynamical anomalies calculated for the years 1991-1993.

\section{Survey on stratospheric volcanic aerosols}

\subsection{Sources and processes}

Stratospheric sulphate aerosols (SSA) are normally supercooled solutions of sulphuric acid $\left(\mathrm{H}_{2} \mathrm{SO}_{4}\right)$ and water vapour produced by gas condensation on pre-existing Aitken nuclei, mostly coming from the tropical tropopause, after an initial coating by $\mathrm{H}_{2} \mathrm{SO}_{4} / \mathrm{H}_{2} \mathrm{O}$ (heterogeneous nucleation). An alternative process may be gas condensation on molecular clusters formed via hetero-molecular homogeneous nucleation of $\mathrm{H}_{2} \mathrm{SO}_{4}$ and $\mathrm{H}_{2} \mathrm{O}$. Sulphuric acid, in turn, is chemically produced by $\mathrm{SO}_{2}$ oxidation, while the main stratospheric sources of sulphur dioxide are short-wave photolysis of carbonyl sulfide (OCS), upward transport from the tropical tropopause and, sporadically direct in situ injection by explosive volcanic eruptions. $\mathrm{H}_{2} \mathrm{SO}_{4} / \mathrm{H}_{2} \mathrm{O}$ homogeneous nucleation is particularly efficient when the sulphuric acid saturation ratio is much larger than unity, i.e. at very cold temperatures (i.e. polar vortex) or primarily under volcanically perturbed conditions of the stratospheric sulphur budget. During the first week after sulphur gas injection into the stratosphere, ultrafine sulphate aerosols with $\mathrm{r}<0.01 \mu \mathrm{m}$ increase by several orders of magnitude (NASA, 1992). Condensation growth and coagulation will then produce optically active particles in the accumulation mode $(\mathrm{r}>0.1 \mu \mathrm{m})$.

The particle size distribution at a given location is determined by simultaneous microphysical processes (heterogeneous and homogeneous nucleation, condensation growth, evaporation, coagulation) and by large-scale transport and 
gravitational sedimentation. Once the particles penetrate downward through the mid-latitude tropopause, they can be removed by wet and dry deposition. This downward motion is mainly produced by large-scale advective transport; gravitational sedimentation is another important removal mechanism, although the lower stratospheric settling deposition is faster than advective downward motion only for particles with radius larger than $1 \mu \mathrm{m}$. This process, however, is important in determining the aerosol vertical profile in the midstratosphere.

The altitude of gas and particulate emission from volcanoes is normally estimated in terms of the volcanic explosivity index, i.e. a logarithmic measure of the magnitude of the eruption, including volume of the ejecta and plume height (Newhall and Self, 1982). Explosive emissions with VEI $<4$ or quiescent degassing disperse the ejecta at different altitudes in the troposphere, depending on VEI or on the altitude of the plate. If VEI $\geq 4$, the injection takes place directly into the stratosphere. As shown by Pinto et al. (1989), emitted gases are essentially $\mathrm{H}_{2} \mathrm{O}, \mathrm{CO}_{2}, \mathrm{SO}_{2}, \mathrm{H}_{2}, \mathrm{CO}, \mathrm{HCl}$, and $\mathrm{HBr}$, with water vapour being the main constituent (about $80 \%$ by volume), and $\mathrm{SO}_{2}$ the most important in terms of climatic impact (about $4.5 \%$ by volume).

Volcanic emissions also consist of solid particles (ash) that have typical radii larger than about $1 \mu \mathrm{m}$ (NASA, 1992). The amount of emitted volcanic dust is highly variable depending on the dust veil index of an explosive eruption (Lamb, 1970). The estimated dust flux reported in IPCC (1994) for the 1980s may vary between lower and upper values of 4 and $10000 \mathrm{Tg} / \mathrm{yr}$, with a 'best' estimate of $33 \mathrm{Tg} / \mathrm{yr}$. The latter is representative of the continuous eruptive activity, and is about two orders of magnitude smaller than soil dust emission. The upper value, on the other hand, is the order of magnitude of volcanic dust mass emitted during large explosive eruptions. The stratospheric lifetime of these coarse particles, however, is only about 1-2 months (NASA, 1992), due to the efficient removal by gravitational sedimentation.

Sulphur emissions occur mainly in the form of $\mathrm{SO}_{2}$, even though other sulphur species may be present in the volcanic plume, namely $\mathrm{H}_{2} \mathrm{~S}$. Nevertheless, the error made, assuming that all the emitted sulphur is in the form of $\mathrm{SO}_{2}$, is likely to be a small one, due to the relatively short $\mathrm{H}_{2} \mathrm{~S}$ lifetime: in the troposphere, typical $\mathrm{OH}$ concentrations will oxidate $\mathrm{H}_{2} \mathrm{~S}$ into $\mathrm{SO}_{2}$ in less than 2 days. In the lower stratospheric midlatitudes, however, the $\mathrm{H}_{2} \mathrm{~S}$ lifetime is of the order of 10 days. This is indeed the case of the 1980 eruption of Mt. St. Helens, when a large $\mathrm{H}_{2} \mathrm{~S}$ output was reported in the gas plume soon after the eruption (Hobbs et al., 1981). In such cases, a delayed formation of $\mathrm{H}_{2} \mathrm{SO}_{4}$ coupled to an efficient removal of large particles by gravitational sedimentation may globally allow for sulphuric acid to condense onto smaller particles, thus prolonging the volcanic SSA residence time into the stratosphere.

The lifetime of volcanic $\mathrm{SO}_{2}$ in the stratosphere is a function of local abundance of $\mathrm{OH}$, so that it may vary depending on the location of the volcanic injection and also on the chemical and optical feedbacks of the emitted $\mathrm{SO}_{2}$ and par- ticles. Modeling studies (Pinto et al., 1989; Bekki et al., 1996) showed that for anomously large $\mathrm{SO}_{2}$ injections (i.e. $\left.>10 \mathrm{Tg}-\mathrm{SO}_{2}\right)$, the $\mathrm{SO}_{2}$ lifetime in the lower stratosphere, as well as the aerosol size and residence time, become dependent on the sulphur loading in a nonlinear way.

\subsection{The Pinatubo case}

Atmospheric effects of the 1991 Pinatubo eruption have been monitored with great detail. An extensive overview of the evolution of the Pinatubo cloud derived from different measurements is given by Russel et al. (1996). The e-folding time for $\mathrm{SO}_{2}$ removal from the stratosphere has been estimated using satellite measurements: estimates are 33 days in the 21-31 km layer from the UARS Microwave Limb Sounder (MLS) instrument (Read et al., 1993) and 35 days from TOMS (Bluth et al., 1992). The e-folding time for aerosol decay in the whole stratosphere is estimated to be 11.4 months from the Stratospheric Aerosol and Gas Experiment (SAGEII) (Weisenstein et al., 1997) and 8.8 months from the Advanced Very High Resolution Radiometer (AVHRR) for the $20 \mathrm{~S}$ to $30 \mathrm{~N}$ region (Grant et al., 1996).

Microphysical processes of aerosol formation and growth are important in determining the actual residence time of volcanic aerosols in the stratosphere. These processes are capable of determining the particle size distribution and then the sedimentation loss rate. To some extent, the stratospheric lifetime of volcanic aerosols is again a function of the location and amount of $\mathrm{SO}_{2}$ injection and also of the time scale of latitudinal transport in the middle atmosphere. The latter, in turn, is partially affected by the phase of the quasi-biennal oscillation of equatorial winds (QBO) and by aerosol heating (Trepte and Hitchman, 1992; Trepte et al., 1993; Pitari, 1993). Interactive numerical simulations of the Pinatubo aerosol evolution (Young et al., 1994; Fairlie, 1995; Timmreck et al., 1999) emphasize the role of aerosol induced heating.

Few months after the eruption, the peak of stratospheric sulphate aerosol mass and optical thickness is reached (Stowe et al., 1992; McCormick et al., 1995). Assuming at this stage a global stratospheric optical depth of the order of 0.15 at $0.55 \mu \mathrm{m}$, a total time of 4 years is needed to come back to the background value of about 0.003 (WMO, 1992; McCormick and Veiga, 1992) using one year as e-folding time for the volcanic aerosol decay. This is of course important in terms of climate forcing: for the Pinatubo case, Hansen et al. (1992) showed that a radiative forcing of about $-4 \mathrm{Wm}^{-2}$ was reached at the beginning of 1992 , decaying exponentially to $0.1 \mathrm{Wm}^{-2}$ in 4 years roughly.

The particle size distribution is also important in determining the actual radiative forcing of a given load of stratospheric sulphate aerosols: Lacis et al. (1992) have shown that the particle effective radius is a critical parameter. Using the El Chichón particle size distributions reported by Oberbeck et al. (1983) and Hofmann and Rosen (1983), they have calculated a tropopause forcing of the order of $-2.5 \mathrm{Wm}^{-2}$ up to about $-5.0 \mathrm{Wm}^{-2}$. These values correspond to an effec- 
tive radius of the order of $0.5 \mu \mathrm{m}$, while the forcing would be about $2 \mathrm{Wm}^{-2}$ at $1.5 \mu \mathrm{m}$, and would even become a positive forcing (i.e. surface warming) with effective radii larger than about $2 \mu \mathrm{m}$. Detailed global model calculations of the Pinatubo aerosol radiative forcing are given by Stenchikov et al. (1998): they have used a combination of SAGE-II aerosol extinction, effective radii retrieved from the Upper Atmosphere Research Satellite (UARS), and other satellite and ground-based observation's to develop a complete set of aerosol parameters for 2 years after the eruption.

The enhancement of the stratospheric sulphate aerosol layer has also the indirect effect of producing more reactive chlorine and bromine through heterogeneous chemical reactions, resulting in additional ozone depletion (Prather, 1992). After the Pinatubo eruption the change in global ozone with respect to 1979 was about twice as large than immediately before the eruption (McPeters et al., 1996). Tropical ozone changes could also be caused by circulation changes due to enhanced radiative heating (Kinne et al., 1992; Schoeberl et al., 1993). The climate forcing of present time stratospheric ozone changes has been estimated to be $0.1-0.2 \mathrm{Wm}^{-2}$, excluding post-Pinatubo years (Hansen et al., 1997; Foster and Shine, 1997). The 1992/94 ozone depletion could then account for a radiative forcing of comparable magnitude, which is, however, much smaller than the direct aerosol forcing from Pinatubo, at least for the first two years following the eruption (roughly -4 to $-1 \mathrm{Wm}^{-2}$ ).

Emissions of water vapour have negligible direct climatic and chemical effects, even if the fraction of water in volcanic gases at the plate is generally greater than $80 \%$ by volume. Typically, the amount of emitted $\mathrm{H}_{2} \mathrm{O}$ would increase the global stratospheric burden of water vapour by no more than about $10 \%$, even for eruptions comparable to Pinatubo. This is because the actual amount of $\mathrm{H}_{2} \mathrm{O}$ reaching the stratosphere is limited by condensation in rising volcanic plumes. For the Earth's largest known eruption of Toba $73 \mathrm{Kyr}$ ago, Bekki et al. (1996) assumed that $27000 \mathrm{Mt} \mathrm{H}_{2} \mathrm{O}$ reached the stratosphere, (about $5 \%$ of the total released water vapour), but even in this extreme case the impact on stratospheric chemistry was found to be small.

On the other hand, two potentially important indirect effects of volcanic $\mathrm{H}_{2} \mathrm{O}$ in the stratosphere should be mentioned: first, the increase in $\mathrm{OH}$ which speeds up $\mathrm{SO}_{2}$ oxidation into $\mathrm{H}_{2} \mathrm{SO}_{4}$, and second, the increase in the homogeneous nucleation rate for the formation of $\mathrm{H}_{2} \mathrm{SO}_{4} / \mathrm{H}_{2} \mathrm{O}$ molecular clusters. The importance of the first indirect effect is limited by the fact that the abundance of $\mathrm{HO}_{x}$ radicals varies as the square root of the concentration of water, while the second effect may increase the stratospheric aerosol lifetime through a less efficient particle removal by sedimentation (there would be more small particles with respect to environmental conditions less favourable to $\mathrm{H}_{2} \mathrm{O} / \mathrm{H}_{2} \mathrm{SO}_{4}$ homogeneous nucleation). Some global model simulations of Pinatubo aerosols including microphysics have shown the importance of homogeneous nucleation in determining aerosol mass and extinction (Ricciardulli et al., 1996; Weisenstein et al., 1997).

\section{Model description and experiment setup}

\subsection{Description of numerical models}

The model used in the present study is a low-resolution threedimensional CCM. The chemical-transport module (CTM) uses a horizontal grid of 19 points in latitude and 18 in longitude $\left(10 \times 20^{\circ}\right.$ resolution $)$ and extends from the ground to about $71 \mathrm{~km}$ altitude. A log-pressure vertical coordinate is used with 26 levels, corresponding to an approximate altitude resolution of $2.84 \mathrm{~km}$, for a total of $19 \times 18 \times 26$ gridpoints. The main features of this model have been described in Pitari and Mancini (2001). All transport fields are taken off-line from a spectral quasi-geostrophic general circulation climate model (GCM). The advective transport is formulated in flux form with the horizontal velocity fields $u, v$ calculated in terms of a velocity stream function and a velocity potential, both taken from the daily output of the GCM (Pitari, 1993). The vertical velocity $w$ is calculated from the mass continuity equation. The numerical scheme for transport is Eulerian fully explicit, using a $1.0 \mathrm{~h}$ time increment.

A small horizontal diffusion is used for numerical stability purposes, being about $10^{6} \mathrm{~m}^{2} \mathrm{~s}^{-1}$ in the troposphere and $2 \times 10^{5} \mathrm{~m}^{2} \mathrm{~s}^{-1}$ in the stratosphere for mid- to high-latitudes. Values in the tropics $(20 \mathrm{~S}-20 \mathrm{~N})$ are one order of magnitude smaller. A vertical diffusion coefficient $\mathrm{K}_{z z}$ is used to simulate those small-scale transport processes not explicitly included in the model. $\mathrm{K}_{z z}$ is assigned with large values in the boundary layer $\left(10 \mathrm{~m}^{2} \mathrm{~s}^{-1}\right)$ decreasing to $0.1 \mathrm{~m}^{2} \mathrm{~s}^{-1}$ in the lower stratosphere at mid-to high-latitudes and to $0.02 \mathrm{~m}^{2} \mathrm{~s}^{-1}$ in the tropics. The effect of gravity wave breaking is simulated by increasing $\mathrm{K}_{z z}$ in the upper stratosphere and mesosphere and using a Rayleigh friction coefficient in the momentum equation in the GCM. Tropospheric convection is included following the scheme described in Muller and Brasseur (1995).

All chemical species are diurnally-averaged; diurnal variations of $\mathrm{N}_{2} \mathrm{O}_{5}$ are parameterized following Brasseur and Solomon (1984), also including the removal from heterogeneous reactions on both sulphate polar stratospheric cloud (PSC) aerosols. Some species are assumed to be present only during daytime $\left(\mathrm{O}, \mathrm{O}\left({ }^{1} \mathrm{D}\right), \mathrm{H}, \mathrm{OH}, \mathrm{HO}_{2}, \mathrm{NO}, \mathrm{Cl}, \mathrm{ClO}, \mathrm{Br}\right.$, $\mathrm{BrO})$. The $24 \mathrm{~h}$ averaged photodissociation rates are calculated daily (i.e. every 24 model hours) and include the effects of Rayleigh and Mie scattering. All medium and shortlived chemical species are grouped in families: $\mathrm{O}_{x}\left(\mathrm{O}_{3}+\mathrm{O}\right.$ $\left.+\mathrm{O}\left({ }^{1} \mathrm{D}\right)\right), \mathrm{NO}_{y}\left(\mathrm{NO}_{x}+\mathrm{HNO}_{3}\right), \mathrm{NO}_{x}\left(\mathrm{NO}+\mathrm{NO}_{2}+\mathrm{NO}_{3}+\right.$ $\left.2 \mathrm{~N}_{2} \mathrm{O}_{5}+\mathrm{HNO}_{4}+\mathrm{PAN}+\mathrm{ClONO}_{2}+\mathrm{BrONO}_{2}\right), \mathrm{HO}_{x}\left(\mathrm{H}_{2} \mathrm{O}_{2}\right.$ $\left.+\mathrm{HO}_{2}+\mathrm{OH}+\mathrm{H}\right), \mathrm{CHO}_{x}\left(\mathrm{CH}_{3} \mathrm{O}_{2}+\mathrm{CH}_{3} \mathrm{OOH}+\mathrm{CH}_{2} \mathrm{O}\right)$, $\mathrm{Cl}_{y}\left(\mathrm{Cl}+\mathrm{ClO}+2 \mathrm{ClOOCl}+\mathrm{HOCl}+\mathrm{ClONO}_{2}+\mathrm{HCl}\right), \mathrm{Br}_{y}$ $\left(\mathrm{Br}+\mathrm{BrO}+\mathrm{HOBr}+\mathrm{BrONO}{ }_{2}+\mathrm{HBr}\right), \mathrm{SO}_{x}\left(\mathrm{SO}_{2}+\mathrm{H}_{2} \mathrm{SO}_{4}\right)$, aerosols. Long-lived and surface-flux species included in the model are $\mathrm{N}_{2} \mathrm{O}, \mathrm{CH}_{4}, \mathrm{H}_{2} \mathrm{O}, \mathrm{CO}, \mathrm{C}_{2} \mathrm{H}_{6}, \mathrm{C}_{2} \mathrm{H}_{4}, \mathrm{C}_{3} \mathrm{H}_{6}$, $\mathrm{C}_{5} \mathrm{H}_{8}, \mathrm{C}_{10} \mathrm{H}_{16}$, other HC, CFCs, HCFCs, halons, OCS, CS DMS, $\mathrm{H}_{2} \mathrm{~S}, \mathrm{SO}_{2}$ for a total of 40 transported species (plus 57 aerosol size categories) and 26 species at photochemical equilibrium. Photochemical terms are calculated with 
the same time frequency of advective tendencies. All photochemical data are taken from JPL (1997), including the heterogeneous reactions on sulphate and PSC aerosols.

The model includes the major components of tropospheric aerosols (sulphate, carbonaceous, dust, sea salt). The size distribution of sulphate (tropospheric and stratospheric) and PSC aerosols are calculated using a fully interactive and mass conserving microphysical code for aerosol formation and growth. Denitrification and dehydration due to PSC sedimentation are calculated explicitly from the nitric acid trihydrate (NAT) and ice aerosols size distribution. The abundance of stratospheric sulphate aerosols is calculated as a function of water vapour and sulphuric acid concentrations (Pitari et al., 1993). The latter is obtained taking into account $\mathrm{OH}$ oxidation of sulphur dioxide, which, in turn, may be perturbed by in-situ injections (as from aircraft or volcanoes).

The general circulation climate model (GCM) is widely described in the literature. For details on the major dynamical features (temperature, wind fields, planetary waves, sudden warmings, radiation, surface temperature balance) and on the ozone prediction capabilities (transport, midlatitude heterogeneous chemistry, polar chemistry, ozone hole, trends), we refer to published papers (Pitari et al., 1992; Pitari, 1993; Pitari et al., 1997; NASA, 1999). In particular, the wave activity in the GCM is sufficiently strong to sporadically produce sudden stratospheric warming events in the Arctic winter months (Pitari et al., 1992), and the $\mathrm{O}_{3}$ climatology (including the Antarctic springtime hole) is normally well reproduced in the model (Pitari, 1993).

\subsection{Experiment setup and model initialization}

The coupling between the two models (CTM and GCM) is made via the dynamical fields (GCM $\Rightarrow \mathrm{CTM}$ ) and via the radiatively active species $\left(\mathrm{H}_{2} \mathrm{O}, \mathrm{CH}_{4}, \mathrm{~N}_{2} \mathrm{O}, \mathrm{CFCs}, \mathrm{O}_{3}\right.$, $\mathrm{NO}_{2}$, aerosols: CTM $\Rightarrow \mathrm{GCM}$ ). The strategy adopted for the present numerical experiment is to run the CTM at steady state with an atmospheric circulation appropriate for 1990. Starting with such a distribution of chemical species, we have run the GCM for 10 consecutive '1990' years after a 2-year spin-up: data averaging over the 10-year simulation allows for a satisfactory filtering of the natural year-to-year dynamical fluctuations in the stratosphere. As a final step, the full CCM has been run 10 times for 1991-1993 starting with the end-of-year dynamical fields from the preliminary 'perpetual 1990' GCM run. In this first experiment, radiation and chemistry codes make use of the interactively calculated aerosols, so that the Pinatubo aerosol radiative feedback on circulation is taken into account in the CCM (experiment ' $I$ ', or 'Interactive aerosols'). Another experiment is made parallel to 'I', but here radiation and chemistry codes use the off-line calculated '1990' pre-Pinatubo sulphate aerosol distribution (experiment 'NI', or 'Non-Interactive aerosols'). The timedependent 1991-1993 CTM simulations include also a parameterization for the dynamical perturbation produced by the QBO: this is a 3D extension of the parameterization de- scribed in Mancini et al. (1991) for a zonally averaged model. In the next section we mostly present the results of our study as an 'I-NI' comparison, after making an average over the 10 independent 1991-1993 simulations for both experiments 'I' and 'NI'.

As initial conditions for the time evolution of Pinatubo particles in the stratosphere, we assume $20 \mathrm{Tg}$ of $\mathrm{SO}_{2}$ (Bluth et al., 1992) to be injected in the model on 15 June 1991 at $15 \mathrm{~N}$ latitude and $120 \mathrm{E}$ longitude, in an altitude layer between 18 and $25 \mathrm{~km}$ (McCormick and Veiga, 1992). We also assume that $10 \mathrm{Tg}$ of volcanic ash have reached the stratosphere in about $24 \mathrm{~h}$ of continuous cataclysmic eruption, i.e. about $0.1 \%$ of the total $10^{16} \mathrm{~g}$ of ejecta from Pinatubo (Bluth et al., 1992). This stratospheric ash fraction may be highly variable depending on the environmental conditions of the rising plume and on the size distribution of ash particles. Textor (1999) has estimated the amount of gas and particles reaching the stratosphere from an explosive volcanic eruption, using the very high resolution ATHAM model developed at the Max-Plank-Institute of Hamburg (Oberhuber et al., 1999; Herzog et al., 1999). At the end of the one hour simulation, $4 \times 0^{-5}$ of the total erupted mass is left in the stratosphere with a maximum of about $20 \%$ after $10 \mathrm{~min}$ : complex microphysical processes (particle growth, sedimentation, etc.) are responsible for this short-time fast removal of stratospheric ash. These results come from plume numerical simulations made under prescribed boundary conditions for the explosion and under a variety of meteorological conditions: since they may not exactly represent the Pinatubo conditions we should treat them as an order of magnitude estimate. Our CCM operates on much longer time scales (one hour to days), so that in order to start the microphysical simulation it is reasonable to assume some rough intermediate value $\left(10^{-3}\right.$ is our choice) for the $24 \mathrm{~h}$ continuous eruption of Pinatubo; the adopted ash size distribution is that of Carey and Sigurdsson (1982) for Mt. St. Helens.

As mentioned in the previous section, the ash climate forcing is of secondary importance due to the rather short lifetime of these coarse particles in the stratosphere (less than one month for $2 \mu \mathrm{m}$ particles at $20 \mathrm{~km}$ altitude). However, they can still play a role by speeding up the removal of sulphuric acid condensed over the ash cores during the first days after the eruption, so that once the sulphur-particle conversion process is completed a somewhat smaller aerosol loading is found in the stratosphere with respect to a reference case without ash particles. Sensitivity studies have been made with our model by changing the stratospheric influx of ash and its size distribution: a very small impact was found on the amount and distribution of radiatively active sulphate aerosols.

The initial injection of water vapour is also specified in the model: Textor (1999) calculates in her experiment that 30000 tons per hour of water reach the stratosphere, together with about 8000 tons of sulphur in an hour of continuous eruption. Part of the emitted water is lost in the troposphere by condensation in the rising volcanic plume and stabilized ash cloud (Pinto et al., 1989). Adopting the same water to 


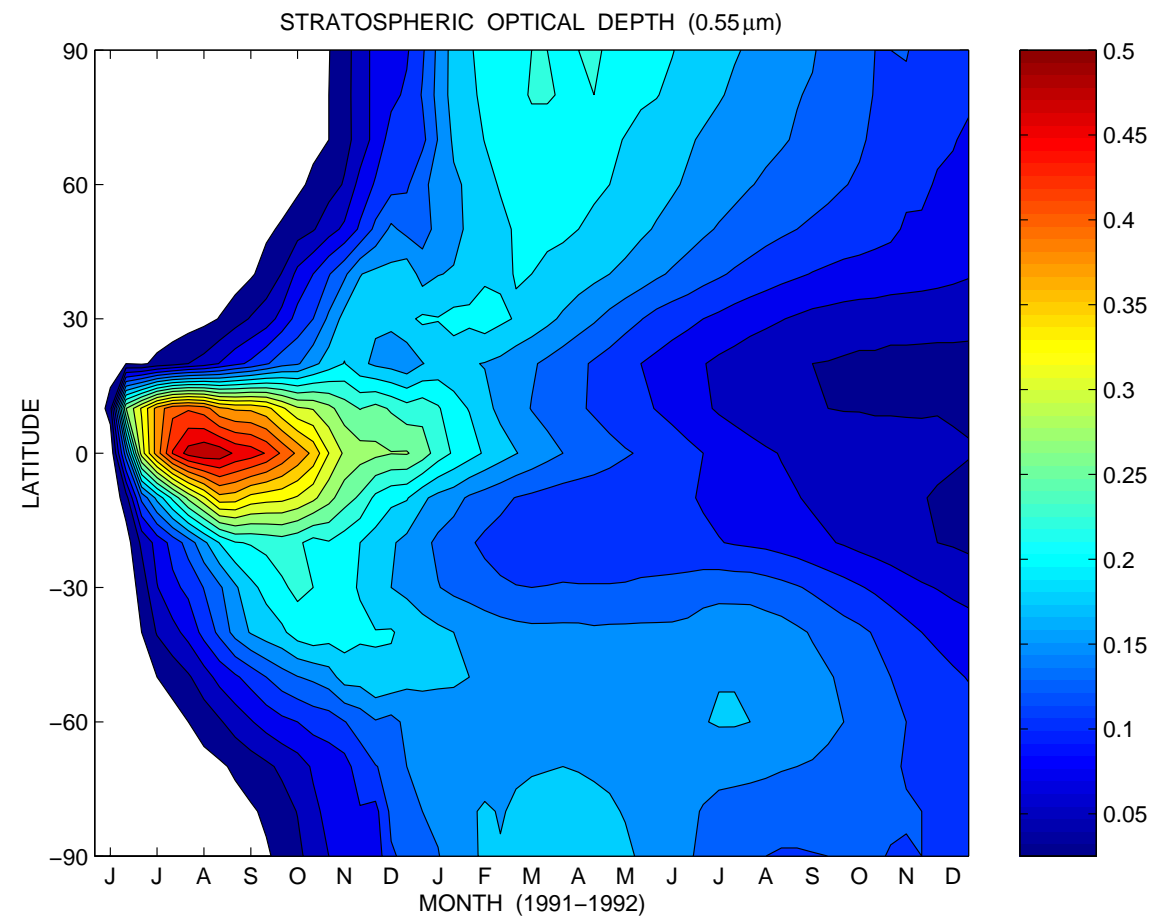

Fig. 1. Time series of calculated stratospheric optical depth at $0.55 \mu \mathrm{m}$ (experiment 'I') as a function of latitude, from June 1991 to December 1992. Contour line spacing is 0.025 . sulphur scaling for Pinatubo (but we remind the reader here that the ratio of water to sulphur could significantly change from one volcanic eruption to another) we obtain $37.5 \mathrm{Tg}$ $\mathrm{H}_{2} \mathrm{O}$ injected in the stratosphere. Textor (1999), however, notes that about $80 \%$ of the total water injected in the stratosphere is in the form of cloud ice and below about $20 \mathrm{~km}$, the water vapour pressure in the volcanic plume is close to its saturation value over ice, so that fast ice particle growth occurs in supersaturated regions. Only above $20 \mathrm{~km}$ the relative humidity become lower than $100 \%$, resulting in reevaporation of ice particles. Keeping in mind these large uncertainties, we assume $10 \mathrm{Tg}-\mathrm{H}_{2} \mathrm{O}$ as an initial condition for our Pinatubo experiment.

As discussed above, stratospheric sulphate particles are normally supercooled solutions of water vapour and sulphuric acid; the latter is formed via $\mathrm{OH}$ oxidation of $\mathrm{SO}_{2}$ with the following reaction sequence (Pinto et al., 1989):

$$
\begin{aligned}
& \mathrm{SO}_{2}+\mathrm{OH}+m \rightarrow \mathrm{HSO}_{3}+m \\
& \mathrm{HSO}_{3}+\mathrm{O}_{2} \rightarrow \mathrm{HO}_{2}+\mathrm{SO}_{3} \\
& \mathrm{SO}_{3}+\mathrm{H}_{2} \mathrm{O} \rightarrow \mathrm{H}_{2} \mathrm{SO}_{4}
\end{aligned}
$$

. This reaction sequence is catalytical in $\mathrm{HO}_{x}$, so that the rate of $\mathrm{SO}_{2}$ conversion to $\mathrm{H}_{2} \mathrm{SO}_{4}$ can remain high throughout the evolution of the volcanic cloud, if enough recycling of $\mathrm{HO}_{2}$ to $\mathrm{OH}$ is present (NASA, 1992). The model calculates a $\mathrm{SO}_{2}$ e-folding time of 40 days, comparable to TOMS observations (35 days); this is an indirect proof of the realistic $\mathrm{OH}$ amount in the model, at least in the tropical lower stratosphere. Details on the microphysical scheme for stratospheric sulphate aerosols can be found in Pitari et al. (1993) and Ricciardulli et al. (1996).

\section{Results}

\subsection{Atmospheric dynamics}

Figure 1 shows the calculated stratospheric optical depth $(\tau)$ at $0.55 \mu \mathrm{m}$ from June 1991 to December 1992 (model run 'I'). The most important features of the calculated time series are the following: (a) good equatorial confinement of the particles up to January 1992, consistent with independent satellite observations (Thomason et al., 1997; Long and Stowe, 1994; Lambert et al., 1993; Stenchikov et al., 1998) and (b) more aerosol transport towards Southern Hemisphere mid-latitudes during the fall months of 1991 (with $\tau$ ranging between 0.14 and 0.20 at $50 \mathrm{~S}$ during October-November, against $0.03-0.10$ at $50 \mathrm{~N})$. The magnitude of the calculated optical depth in the Southern Hemisphere is closer to AVHRR observations $(0.15-0.20$ at $0.5 \mu \mathrm{m})$ than to SAGEII values (about 0.12 at $0.525 \mu \mathrm{m}$ ).; (c) The aerosol penetration in the Northern Hemisphere mid-high latitudes becomes relatively fast only in late winter $1991 / 92$ with $\tau \simeq 0.18$ 0.20 at $50 \mathrm{~N}$ during February-March 1992, which is close to SAGE-II observations (0.16-0.18); (d) during the first six months, tropical $\tau$ values are closer to AVHRR observations, with respect to SAGE-II; (0.46 in September 1991 and 0.18 in March 1992 at the equator, against 0.38-0.24 for AVHRR, and $0.21-0.17$ for SAGE-II): we have applied here a 0.84 correction factor to the AVHRR values from June to December 1991, as recommended by Russel et al. (1996). In addition, it should be taken into account that optical depth calculations from SAGE-II extinction data are difficult during the first months after the eruption due to instrument saturation problems at the aerosol peak altitudes. 


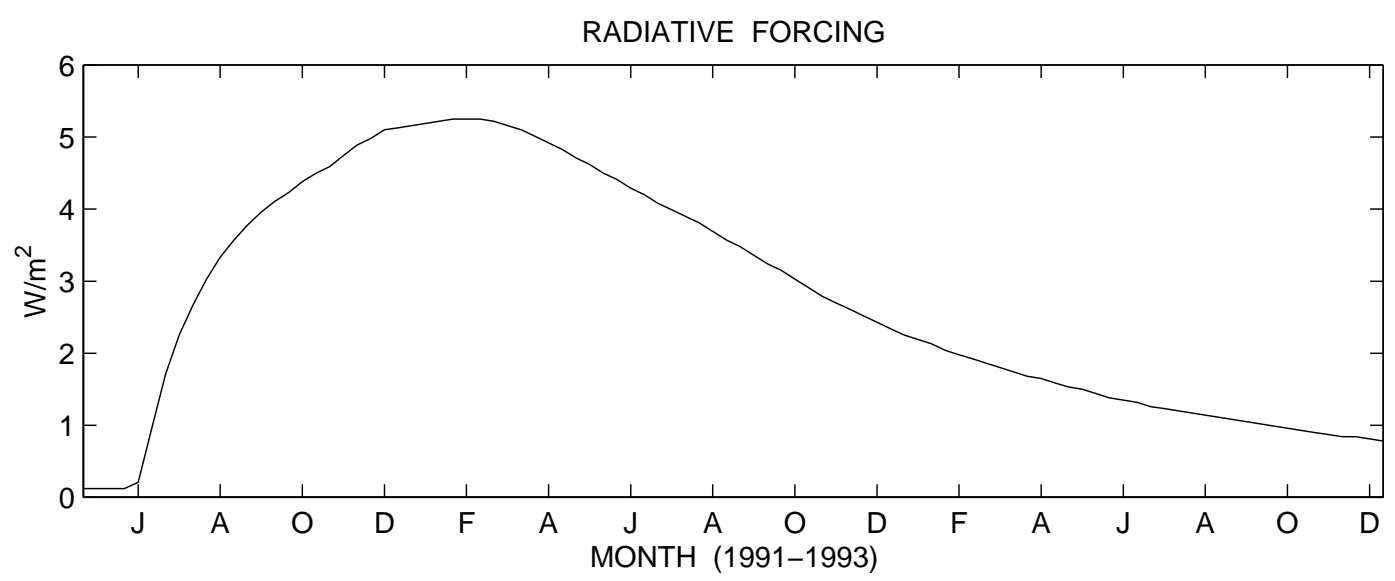

Fig. 2. Time series of the calculated globally averaged net radiative flux change at the tropopause (1991-1993) due to aerosols from the Pinatubo eruption. Units are $\mathrm{W} / \mathrm{m}^{2}$.

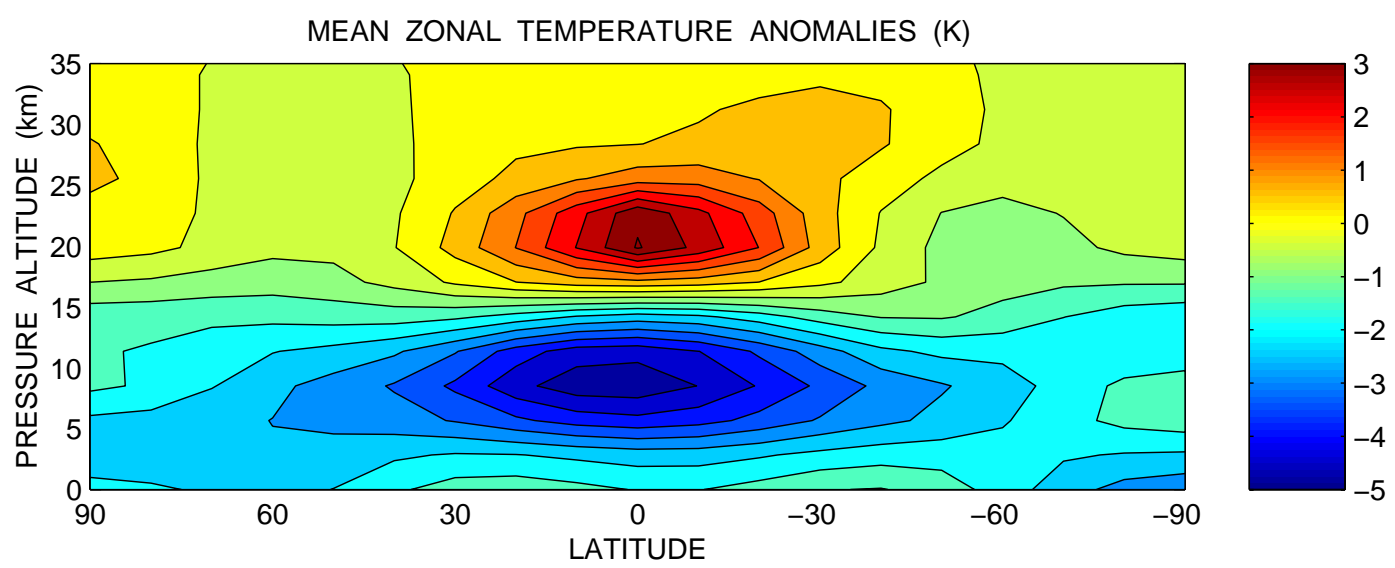

Fig. 3. Model calculated mean zonal temperature changes produced by Pinatubo aerosols during September-November 1991 (K) (experiment 'I-NI'). Contour line spacing is $0.5 \mathrm{~K}$.

As discussed in Timmreck et al. (1999), the aerosol radiative interaction helps the tropical maximum to move equatorward with respect to the initial position, although the observed meridional transport across the equator would be faster than the calculated one, even including the aerosol radiative feedback on dynamics (as it will be discussed later, this radiative perturbation tends to increase the meridional southward component of the residual velocity). In order to help this cross-equatorial transport, we have superimposed on the GCM-calculated velocity stream-function a perturbation field resembling a strong high over Tibet: this dynamical pattern was present during June 1991 and favoured the southward motion of the gas and aerosol volcanic cloud.

About three months after the eruption, gas to particle conversion processes are completed and coarse ash particles from the lower stratosphere form sediment. From this moment (and for about one year), our calculations predict a size distribution in the aerosol cloud with an effective radius of the order of 0.4-0.6 $\mu \mathrm{m}$, to be compared with about $0.15 \mu \mathrm{m}$ in pre-volcanic conditions. As shown by Lacis et al. (1992), the climate forcing of sulfuric acid droplets of this size is always negative, because additional scattering of incoming short-wave solar radiation dominates over the additional infrared forcing; only much larger particles $\left(\mathrm{r}_{e f f}>2 \mu \mathrm{m}\right)$ could cause heating of the surface. Figure 2 shows the globally averaged net radiative flux change at the tropopause as calculated in the model up to December 1993. The largest forcing is found during February 1992 $\left(-5.2 \mathrm{~W} / \mathrm{m}^{2}\right.$, with $\left.\tau=0.175\right)$, decreasing later on with an efolding time of 12 months (about $-1.2 \mathrm{~W} / \mathrm{m}^{2}$ during August 1993: see also Hansen et al., 1992).

Figure 3 presents the model calculated temperature changes produced by the volcanic aerosols during September-November 1991: as expected from the above discussed radiative flux change, the troposphere cools down $(-1.5 \mathrm{~K}$ globally at the surface), while the tropical lower stratosphere is heated by aerosol absorption of solar and planetary radiation and by $\mathrm{O}_{3}$ absorption of particle diffuse radiation (Pitari, 1993). The maximum cooling is found in the tropical mid-upper troposphere $(-4.8 \mathrm{~K}$ at $300 \mathrm{hPa})$ and is produced by decreasing convective heating. The globally averaged temperature gradient between $300 \mathrm{hPa}$ 
CALCULATED TEMPERATURE CHANGES (30-50hPa): SEPTEMBER 1991

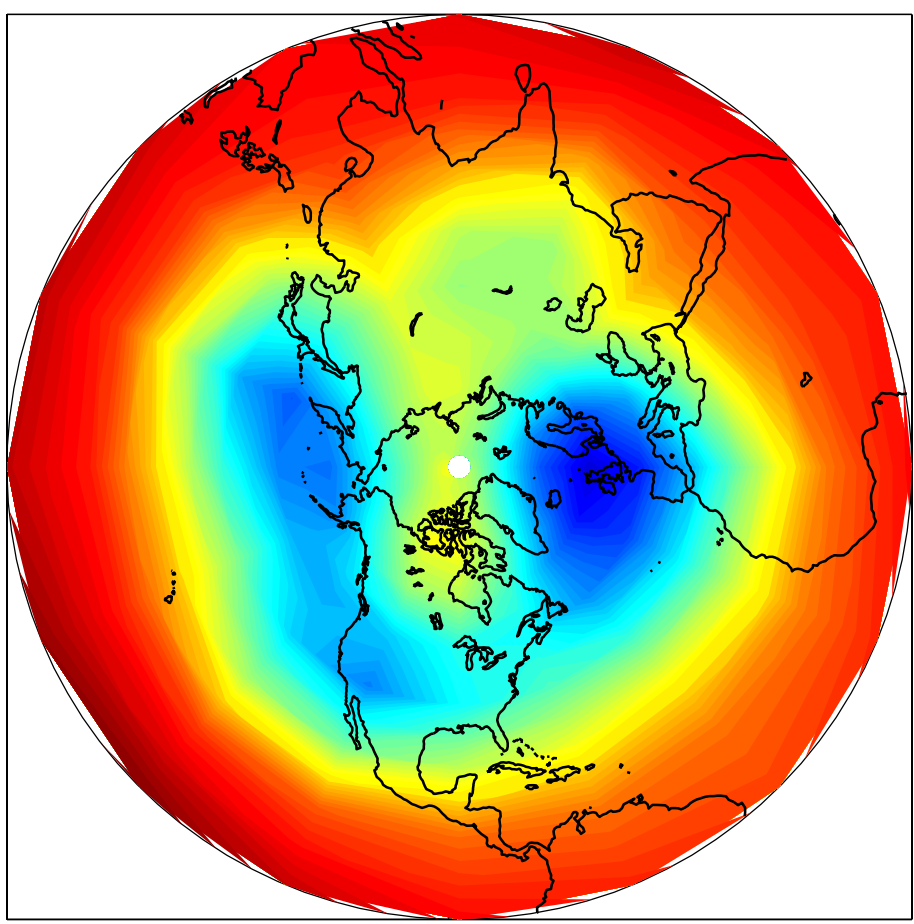

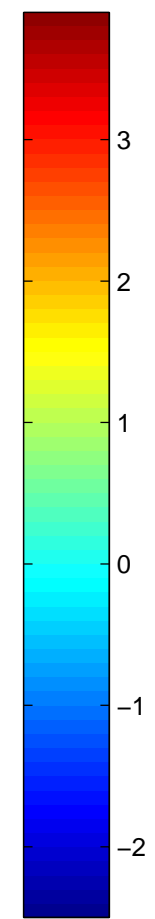

Fig. 4. Calculated Northern Hemisphere temperature anomalies at 30 $50 \mathrm{hPa}$ during September 1991 (K) (experiment 'I-NI'). and the surface decreases from $-6.3 \mathrm{~K} / \mathrm{km}$ to $-6.8 \mathrm{~K} / \mathrm{km}$ and the static stability parameter $\left(\mathrm{HdT} / \mathrm{dZ}+\mathrm{RT} / \mathrm{C}_{p}\right)$ from $31.1 \mathrm{~K}$ to $29.1 \mathrm{~K}$ at $300 \mathrm{hPa}$. We find this lower atmospheric stability to significantly affect the activity of planetary waves in the Northern Hemisphere winter season following the eruption (see ahead). The maximum stratospheric warming is calculated at the equator at about $30-50 \mathrm{hPa}(3.5 \mathrm{~K})$ : in this altitude layer a cooling belt is present between $40 \mathrm{~N}$ and $70 \mathrm{~N}(-0.2 \mathrm{~K}$ to $-0.4 \mathrm{~K})$ similarly to what has been observed (Labitzke and McCormick, 1992). A comparison of calculated and observed lower stratospheric $\Delta \mathrm{T}$ maps is presented in Fig. 4 and Fig. 5; observed changes are obtained by subtracting a 20-year climatology (1965-1984) to the 1991 measurements collected by Kuhlbarsch and Naujokat (1991). The qualitative features of the observed extratropical temperature anomaly are well represented in our calculation, showing a wide area of mid-latitude cooling with evidence of wave-number 1 and 2 activity.

Changes in solar and planetary heating rates due to volcanic aerosols have the direct effect of warming up the tropical stratosphere, and also upsetting the stratospheric dynamics because no radiative equilibrium is achieved. In particular, an additional residual upwelling motion is produced in the tropical stratosphere as a result of a stronger pole-toequator gradient of net heating rates. Figure 6 presents the calculated residual vertical velocity $\left(\mathrm{w}^{*}\right)$ averaged over $15 \mathrm{~N}-$ $15 \mathrm{~S}$ and the 1991 fall season months (September-OctoberNovember, SON): a $20 \%$ increase is found at $30 \mathrm{hPa}$ during 1991 with respect to the non-interactive case. It is worth noting that the calculated velocity $(0.3 \mathrm{~mm} / \mathrm{s})$ is con- sistent with the value derived from the tape recorder signal of $\mathrm{H}_{2} \mathrm{O}+2 \mathrm{CH}_{4}$, using the Halogen Occultation Experiment (HALOE) data.

Figure 7 summarizes the calculated residual circulation changes as an annual average over July 1991 through June 1992 with respect to the non-interactive case. The most relevant features are the following: (a) additional upwelling above $75 \mathrm{hPa}$ in the $15 \mathrm{~N}-15 \mathrm{~S}$ latitude band; (b) additional southward motion in the Southern Hemisphere in a layer centered at $20 \mathrm{~km}$ altitude; (c) rather strong additional subsidence in the Northern Hemisphere at mid- and high-latitudes, with a southward meridional component in the lower stratosphere below $50 \mathrm{hPa}$. Feature (a) may explain the observed ozone loss in the tropics during the 1991 fall season (Grant et al., 1996), while (b) is consistent with the observed particle spread in the Southern Hemisphere during the austral late winter and fall of 1991 (McCormick and Veiga, 1992; Long and Stowe, 1994), and finally (c) may help explain the pronounced tropical confinement of the aerosol particles (Lambert et al., 1993) by decreasing their isentropic poleward motion in the 400-500 K layer (Timmreck et al., 1999).

Trepte and Hitchman (1992) have studied the tropical stratospheric circulation using satellite aerosol data and have clearly shown the differences between dynamical regimes during dominant easterly or westerly shear of the quasibiennial oscillation of the equatorial stratosphere. The streamlines of the QBO circulation are summarized in Fig. 8, showing that definite upwelling motions are extended everywhere in the tropical stratosphere (from the tropopause up to $30 \mathrm{~km}$ altitude) during years with dominant easterly 
OBSERVED TEMPERATURE CHANGES (30hPa): SEPTEMBER 1991

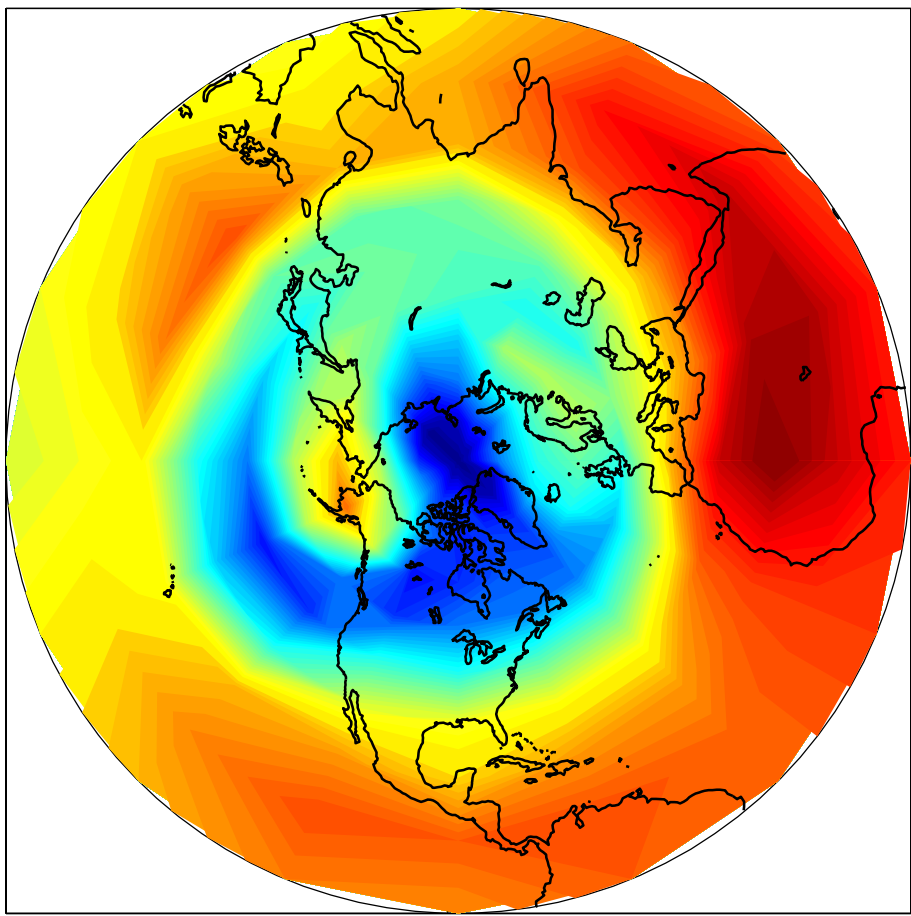

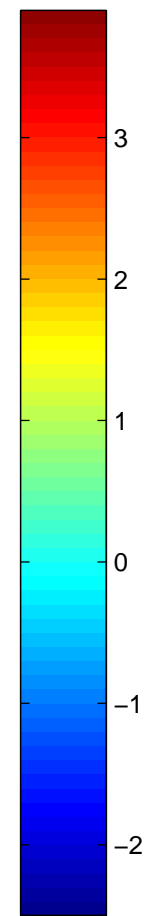

Fig. 5. Observed Northern Hemisphere temperature anomalies at $30 \mathrm{hPa}$ during September 1991 (K) (Labitzke and McCormick, 1992). Changes are obtained by subtracting a 20-year climatology (1965-1984) from the 1991 measurements collected by Kuhlbarsch and Naujokat (1991).
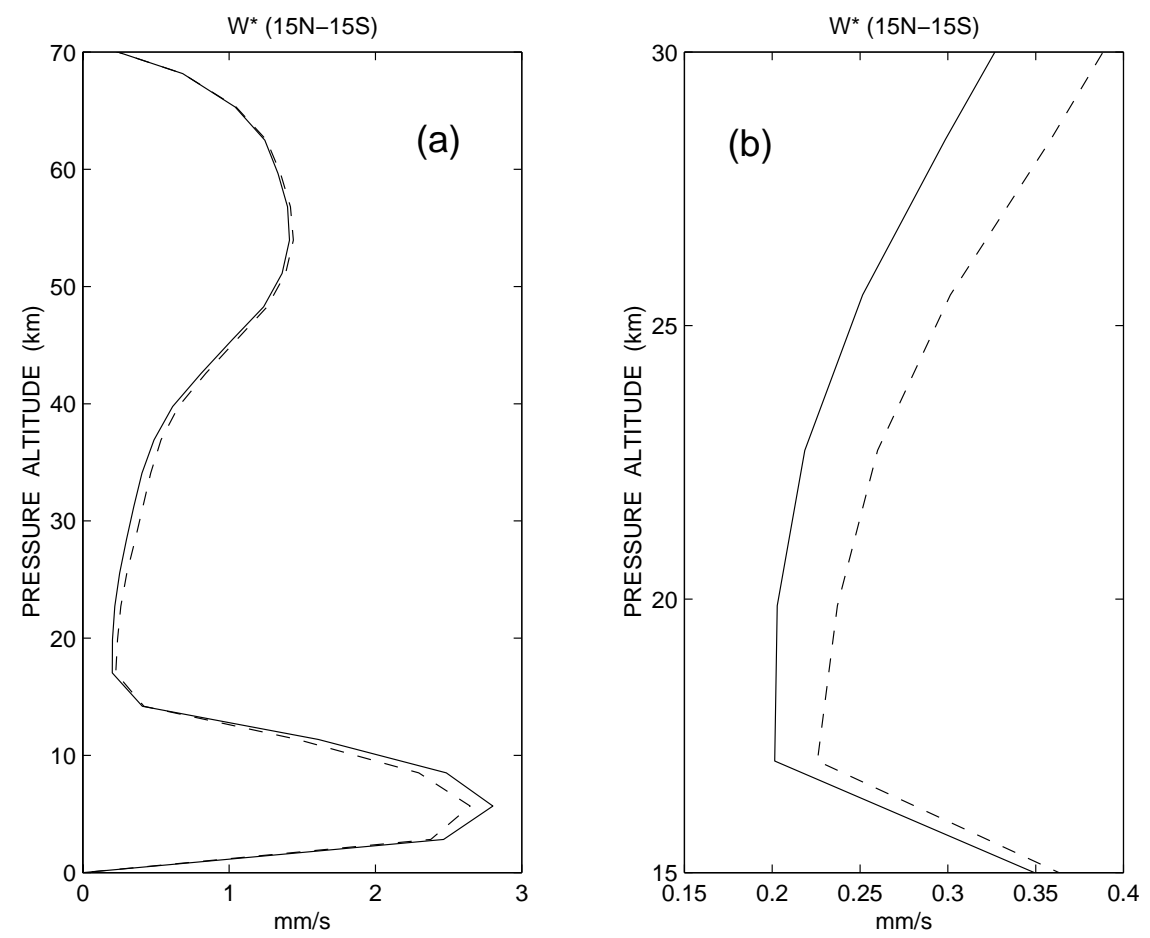

Fig. 6. Calculated equatorial residual vertical velocity $(15 \mathrm{~N}-15 \mathrm{~S})$ for 1991 September-October-November months (SON) with interactive (dashed lines) and non-interactive aerosols (solid lines) (a); (b) inset of the left panel (a) in the lower stratospheric region. Units are $\mathrm{mm} / \mathrm{s}$.

shear (Fig. 8a). On the other hand, during westerly phase years, descent relative to the mean stratospheric circulation occurs over the equator and more aerosols can be transported down to altitudes within a few kilometers above the tropopause, where poleward isentropic transport is relatively fast (Fig. 8b). The main conclusion of Trepte and Hitchman
(1992) is that when the QBO easterly shear is present (as in the months following the Pinatubo eruption), aerosols are lofted over the equator and less transport towards the poles is obtained with respect to the case of westerly shear. Model results shown in Fig. 6 and Fig. 7 suggest that the Pinatubo aerosol radiative heating has a feedback on the dynamics of 

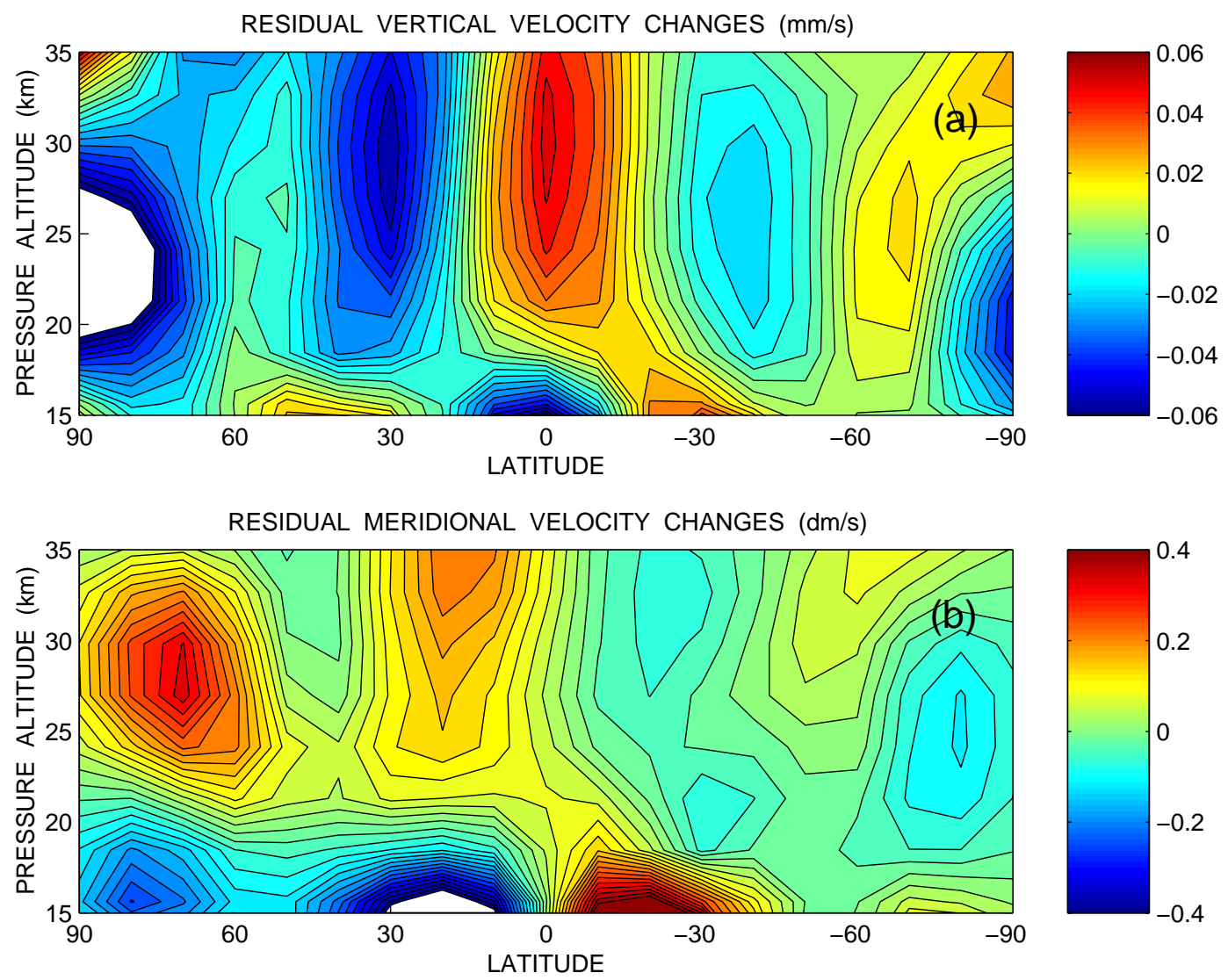

Fig. 7. Calculated residual circulation changes averaged over July 1991 through June 1992 (experiment 'I-NI'). Upper and bottom panels ((a), (b)) are for vertical and meridional components, respectively. Units are $\mathrm{mm} / \mathrm{s}$ in (a) and $\mathrm{dm} / \mathrm{s}$ in (b). Contour line spacing is $0.005 \mathrm{~mm} / \mathrm{s}$ in (a) and $0.025 \mathrm{dm} / \mathrm{s}$ in (b).

the middle atmosphere similar to that of QBO easterly phase years and may additionally help to confine the particles in the tropical reservoir and to increase their lifetime.

The similarities between dynamical anomalies calculated as a result of the Pinatubo aerosol radiative forcing with those observed for the QBO easterly phase may also be seen in the lower stratospheric geopotential height field. Our results suggest that the tropical volcanic aerosol heating forces changes in the planetary wave amplitude similar to those observed during years with easterly (E) phase of the QBO with respect to westerly (W) phase years. Figure 9 shows the amplitude change of the $50 \mathrm{hPa}$ geopotential wave-number 1 during winter 1991/92, due to the volcanic aerosol radiative feedback: this change is compared to that obtained from a statistic over 16 years of observations (1962-1977) made by grouping years with dominant $\mathrm{E}$ or $\mathrm{W}$ phases of the QBO (Holton and Tan, 1980). In early winter months (NovemberDecember) the amplitude of the 1991 wave-number 1 is found to be nearly $45 \%$ stronger than it would have been without aerosol radiative interaction, similar to what was found by Holton and Tan (1980) for easterly versus westerly years (40\%). Holton and Tan (1980) hypothesize that shifts in the latitude of the zero mean zonal wind critical line associated with the equatorial QBO may be responsible for the $50 \mathrm{hPa}$ extratropical behaviour of planetary waves. They also conclude, however, that the significant differences between the mean zonal wind distributions in $\mathrm{E}$ and $\mathrm{W}$ categories could also be an alternative (or additional) explanation for the different amplitude and phase behaviour of the waves. For 1991/92 we may hypothesize that the enhanced lower stratospheric planetary wave activity is a direct consequence of the decreased atmospheric stability produced by the aerosol induced tropospheric cooling (Fig. 3). As in the observations, we also find a rather distinct wave behaviour between early and late winter months: from January through March 1992 the amplitude of wave number 1 shows no significant differences between 'I' and 'NI' cases, as observed for E-W years. The calculated anomalies of wave number 2 during 1991/92 late winter months are also rather small, while Holton and Tan (1980) observed a 60\% stronger amplitude during westerly phase years: the authors, however, suggest that this wave number 2 signal could most likely be a result of sampling fluctuations rather than a real difference between $\mathrm{W}$ and $\mathrm{E}$ categories.

Geopotential height field deviations for December 1991 are shown in Fig. 10 ('I-NI'). As observed for E-W year anomalies, the effects of planetary wave modulation is much stronger in early winter months, while for late winter, the 

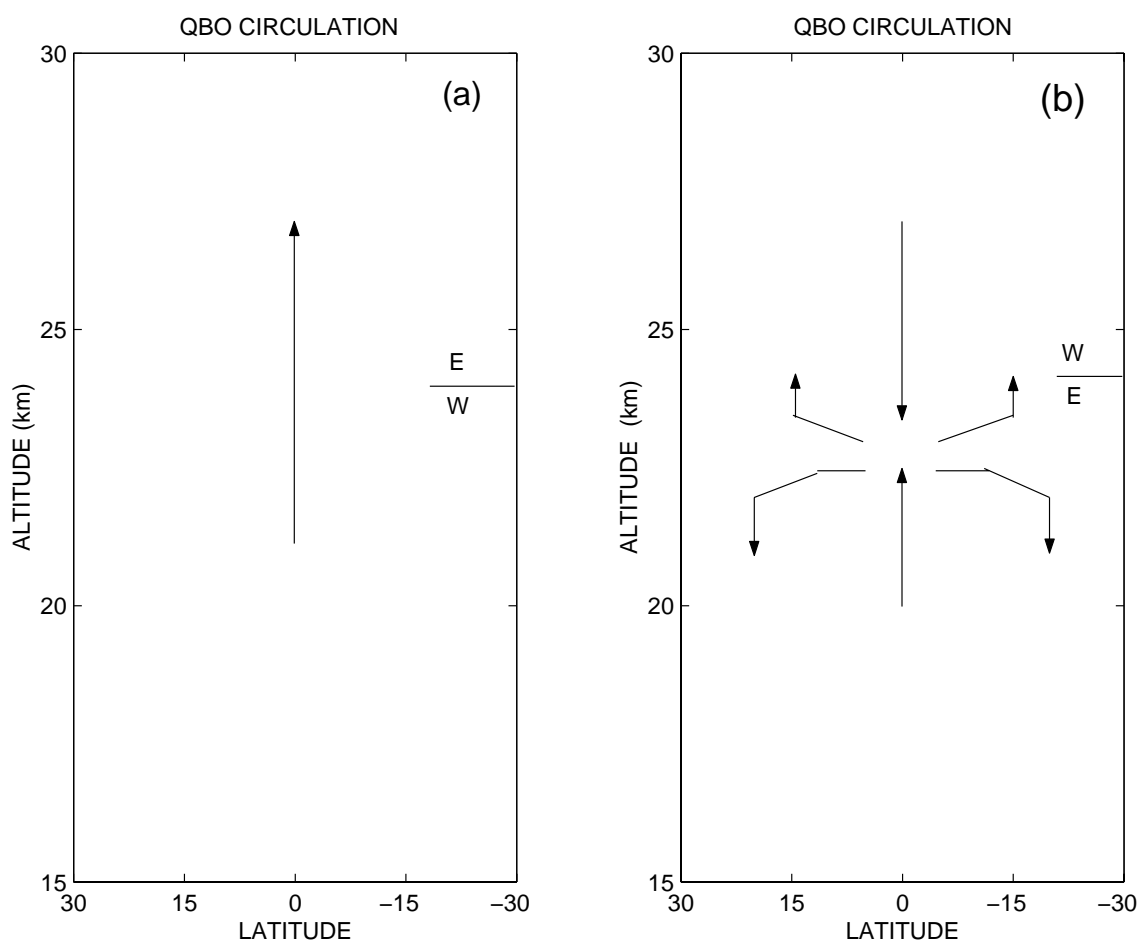

Fig. 8. Streamlines of the QBO circulation inferred from observed aerosol distributions. Panel (a) is for dominant easterly shear (October 1988); panel (b) is for dominant westerly shear (November 1984) (Trepte and Hitchman, 1992).

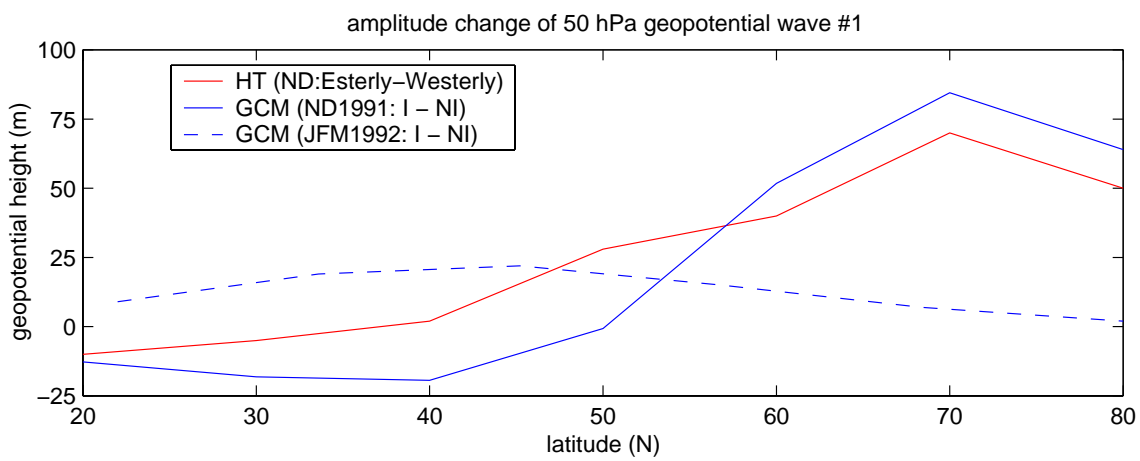

Fig. 9. Amplitude change in the $50 \mathrm{hPa}$ geopotential wave number $1 \mathrm{~m}$ ) during winter 1991/92 calculated with respect to the baseline simulation with no radiative feedback of the volcanic aerosols ('I-NI') (solid blue line is for November-December 1991; dashed blue line is for January-February-March 1992). Red line shows the corresponding amplitude anomaly for November-December months, resulting from over 16 years of observations (1962-1977) made by grouping years with dominant E, W phases of the QBO (Holton and Tan, 1980).

high-latitude geopotential height deviations are much more zonally symmetric. A direct comparison can be made with Holton and Tan (1980) values for E-W during December months (Fig. 11): the qualitative agreement is consistent with the above discussed $40 \%$ increase in wave number 1's amplitude. Summarizing, we conclude that the tropospheric cooling produced by the Pinatubo aerosol climate forcing, coupled to the tropical stratospheric radiative heating, may produce middle-atmosphere circulation changes resembling those associated with the easterly phase of the equatorial QBO, both in terms of mean meridional circulation and planetary wave activity. It is also worth noting that the above described enhancement of planetary wave activity may, to a large extent, explain the more pronounced additional downwelling in the Northern Hemisphere residual circulation with respect to the Southern Hemisphere (Fig. 7).

\subsection{Long-lived tracers}

Substantial perturbations in the trends of greenhouse gases (in particular $\mathrm{CH}_{4}, \mathrm{~N}_{2} \mathrm{O}$ and $\mathrm{O}_{3}$ ) occurred during 1992 (Schauffler and Daniel, 1994; WMO, 1999). While ozone is mainly produced in the stratosphere via UV photolysis of molecular oxygen and is photochemically depleted via complex catalytic cycles, $\mathrm{CH}_{4}$ and $\mathrm{N}_{2} \mathrm{O}$ are mainly produced 
GEOPOTENTIAL HEIGHT DEVIATIONS (M): DEC1991 I-NI

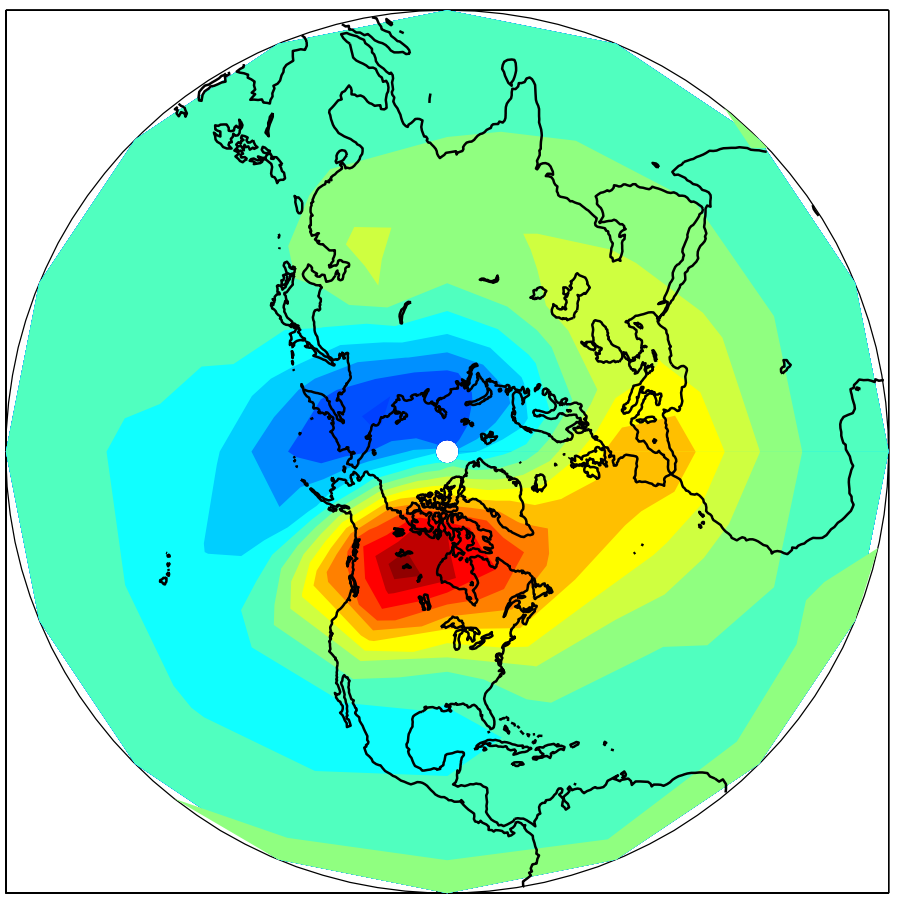

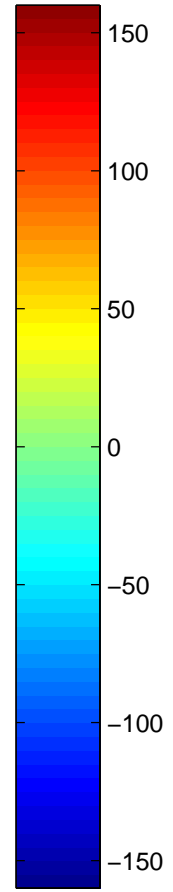

Fig. 10. Geopotential height field deviations (m) for December 1991, calculated as in Fig. 9. at the surface or in the troposphere and have a rather long chemical lifetime (about 10 years for methane and 150 years for nitrous oxide, considering both troposphere and stratosphere). Drawing conclusions on ozone trends is made difficult by the complex chemical-radiative-dynamical feedback processes involved, whereas the picture should be clearer for $\mathrm{CH}_{4}$ and $\mathrm{N}_{2} \mathrm{O}$.

The average pre-Pinatubo rate of increase in atmospheric mixing ratios of $\mathrm{CH}_{4}$ declined consistently during 1992 in the Northern Hemisphere (from 11.6 to $1.8 \mathrm{ppbv} / \mathrm{yr}$ ) (Dlugokencky et al., 1994), and a similar behaviour was found for $\mathrm{N}_{2} \mathrm{O}$ (from 1.0 to $0.5 \mathrm{ppbv} / \mathrm{yr}$ ) (Swanson et al., 1993). Changes in both hemispheres began in the second half of 1991; the Southern Hemisphere trends also decreased, but only by smaller amounts. Schauffler and Daniel (1994) have proposed a physical mechanism that may explain these observations: since the stratosphere contains lower mixing ratios of these gases, a decline in the observed trends could result from a higher degree of exchange between the stratosphere and the troposphere. The above described anomalies of the stratospheric circulation (radiatively forced by the Pinatubo aerosols) could indeed increase the midlatitude stratosphere-troposphere flux of atmospheric tracers. It should be noted that not only the extratropical additional downwelling of the mean meridional circulation is important in this regard, but also the enhancement in wave activity: this is expected to further enhance the meridional circulation and the stratosphere-troposphere flux (Holton, 1990).

The box-model used in the Schauffler and Daniel (1994) study was probably not optimal to study these strat/trop exchanges. Our CCM simulation may better address this point, by looking directly at the tropopause anomalies of tracers, calculated as the difference between the simulation including the aerosol radiative forcing and the other simulation treating Pinatubo aerosols as a passive tracer, with no radiative feedbacks on the atmospheric circulation. Figure 12 is a time series of the observed NH methane trend and superimposed shows the calculated tropopause anomalies produced by the circulation changes due to the Pinatubo aerosol radiative feedback. The extratropical downwelling branch of the perturbative residual circulation (Fig. 7) is the main driving mechanism for this tropopause decrease in methane: the overall effect will be to dilute the troposphere with stratospheric air that is poorer in $\mathrm{CH}_{4}$ (or $\mathrm{N}_{2} \mathrm{O}$ ). Figure 12 indicates that the stratospheric circulation changes forced by volcanic aerosols during 1991/92 are responsible for an average hemispheric mixing ratio change at the tropopause (100$200 \mathrm{hPa}$ ), compatible with the observed trend decline, at least through the spring of 1992.

It is also useful to compare the calculated tropopause anomalies in the two hemispheres (Fig. 13): as observed for the trend decline, $\mathrm{SH}$ tropopause changes of both methane and nitrous oxide are smaller than NH changes. This evidence is consistent with the calculated anomalies of the residual circulation: as a result of the increased planetary wave activity during the 1991/92 Northern Hemisphere winter months, the downwelling branch of the perturbative residual circulation is much more pronounced in the Northern Hemisphere than in the Southern (Fig. 7). It should also be noted that our predicted tropopause change of nitrous oxide is larger than the observed trend decline; one possible explanation could be that our model overestimates some additional 
GEOPOTENTIAL HEIGHT DEVIATIONS (M): DEC E-W

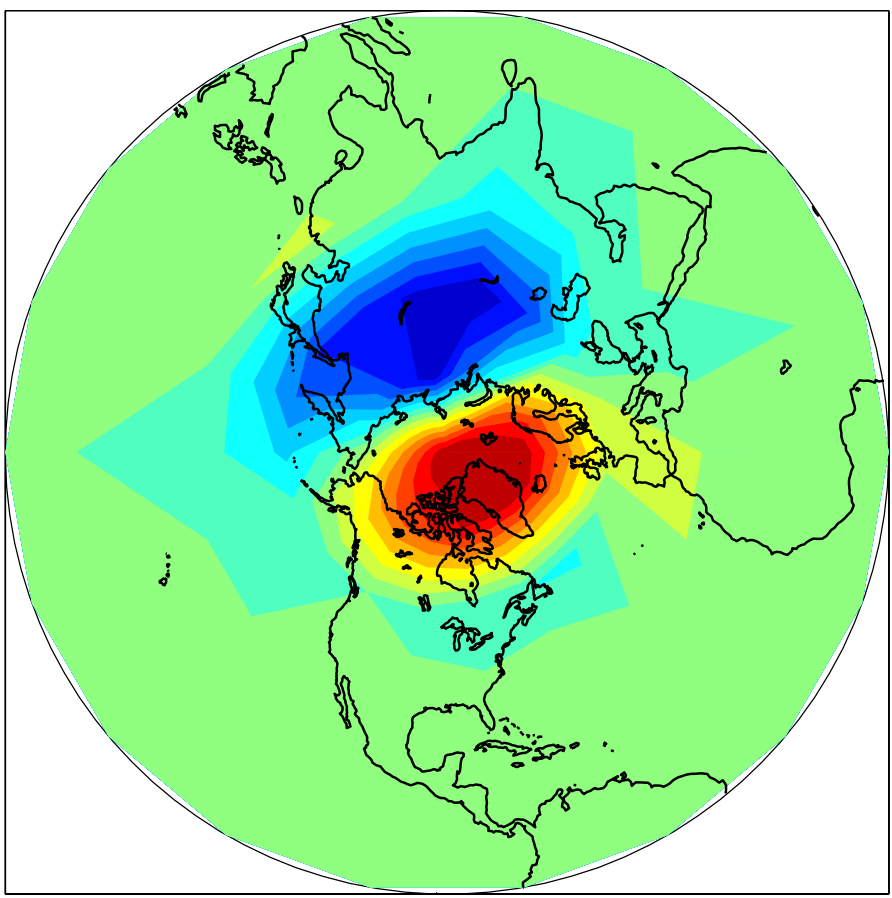

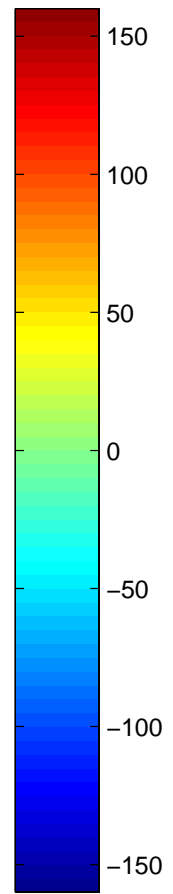

Fig. 11. Observed E-W geopotential height field deviations $(\mathrm{m})$ for December months (1962 to 1977) (Holton and Tan, 1980). mid-stratospheric $\mathrm{N}_{2} \mathrm{O}$ photodissociation due to the aerosol diffuse radiation.

As noted before, the observed $\mathrm{O}_{3}$ behavior during 1991/92 is more difficult to explain with respect to methane and nitrous oxide, due to the strong feedback of heterogeneous chemistry on radical species affecting lower stratospheric ozone depletion. The time-dependent model exercise carried out for WMO (1999), as well as independent studies (Solomon et al., 1996), have proved that changes in stratospheric sulphate aerosols coupled to trends of $\mathrm{Cl} / \mathrm{Br}$ species may, to a large extent, explain the ozone trend observed in the last two decades. Volcanic eruptions of different magnitude (El Chichón, Nevado del Ruiz, Pinatubo, and others) represent the most important factor affecting stratospheric aerosols. An increase in particle number density or a change in size distribution with enhanced concentration of smaller particles may significantly increase the aerosol surface area density available for heterogeneous chemical reactions. These reactions (hydrolysis of $\mathrm{N}_{2} \mathrm{O}_{5}$ is the most important at mid-latitudes) have the overall effect of reducing the amount of reactive nitrogen in the lower stratosphere, so that more $\mathrm{OH}, \mathrm{ClO}$ and $\mathrm{BrO}$ are simultaneously produced, also because other heterogeneous reactions may directly convert part of the stable $\mathrm{Cl} / \mathrm{Br}$ reservoirs $(\mathrm{HCl}$, in particular) into active $\mathrm{Cl} / \mathrm{Br}$ radicals. These chemical perturbations end up producing more ozone depletion, at least below $25 \mathrm{~km}$ altitude. All models participating in the WMO (1999) exercise have shown a great chemical sensitivity to the Pinatubo aerosol perturbation, which is the largest in the past two decades.

Pure chemical studies, however, do not take into account the aerosol radiative effects both on photolysis rates (Pitari and Rizi, 1993) and, more importantly, on stratospheric dynamics. A common feature in the WMO (1999) intercomparison is that no model is able to reproduce the observed additional $\mathrm{O}_{3}$ depletion during 1993 with respect to 1992 (at least with a magnitude comparable to TOMS measurements, that is about 2\%). We hypothesize here that the above discussed changes of the stratospheric circulation could be responsible for this observed additional ozone depletion during 1993, both directly (by perturbing the lower stratospheric ozone fluxes) and indirectly (via the aerosol distribution affecting the ozone chemical balance).

Figure 14 compares TOMS measurements with the calculated global ozone changes relative to 1991 for the two cases (radiatively interactive and non-interactive aerosols). Model $\mathrm{O}_{3}$ changes are obtained from four different numerical experiments: 'I' and 'RNI' in panel (a), 'CNI' and 'NI' in panel (b). ' $\mathrm{I}$ ' is the already discussed fully interactive aerosol case (radiation + chemistry), and 'RNI' is the radiatively noninteractive case with photochemistry using the on-line calculated aerosol distribution. 'CNI' is the radiatively interactive case with photochemistry using the 1990 background sulphate aerosols, and 'NI' is the already discussed fully non-interactive case (radiation + chemistry). In other words, panel (a) shows the effect of updating the stratospheric circulation with a realistic 1991-93 photochemistry, while panel (b) shows the same dynamical effects on ozone but using a pre-Pinatubo 'volcanically-clean' photochemistry.

As expected, the first information from Fig. 14 is that the strongly enhanced heterogeneous chemistry during 1992/93 is the key factor for explaining the observed $\mathrm{O}_{3}$ decline: the negative ozone trend in panel (b) is simply a result of the in- 


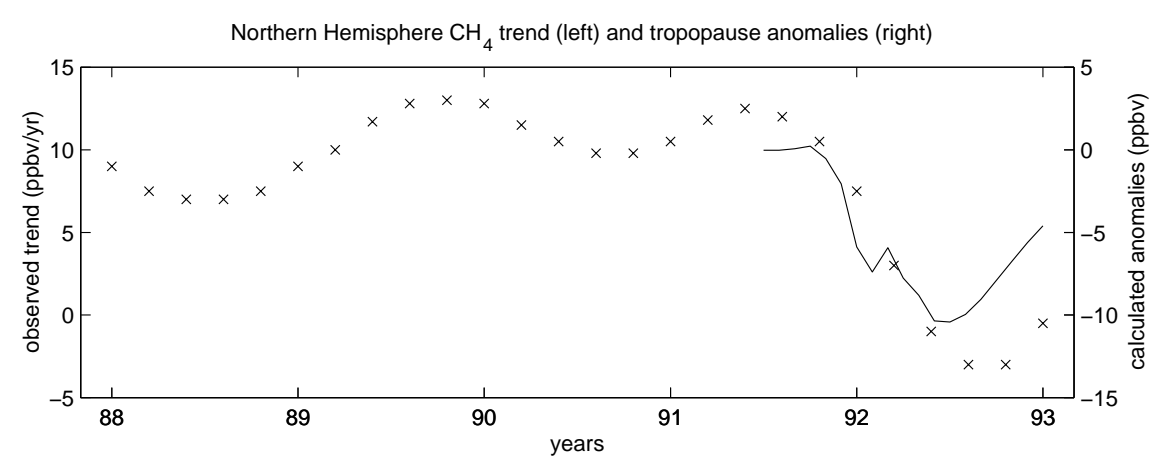

Fig. 12. Time series of the observed methane trend (left scale, ppbv/yr) (Dlugokencky et al., 1994) and calculated tropopause anomalies produced by the Pinatubo circulation changes (right scale, ppbv). Both quantities are averaged over the Northern Hemisphere.
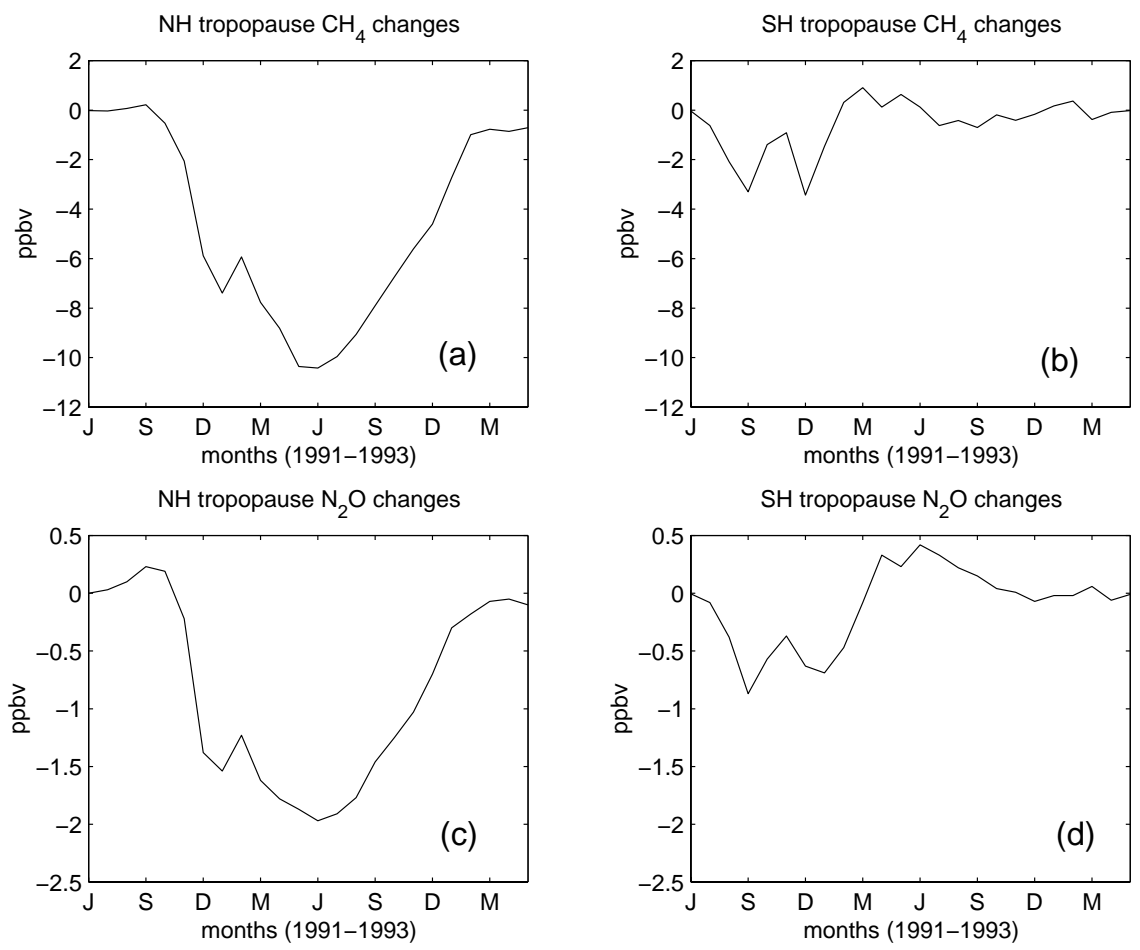

Fig. 13. Time series of the calculated tropopause anomalies of $\mathrm{CH}_{4}$ (upper panels (a), (b)) and $\mathrm{N}_{2} \mathrm{O}$ (bottom panels (c), (d)). Left panels $((\mathrm{a}),(\mathrm{c}))$ are for the Northern Hemisphere, right panels $((\mathrm{b}),(\mathrm{d}))$ for the Southern Hemisphere. Units are ppbv.

creasing $\mathrm{Cl} / \mathrm{Br}$ loading in the stratosphere, but its magnitude is much smaller than the observed one. It should be noted, however, that the radiatively forced circulation changes are able to modulate the global $\mathrm{O}_{3}$ loss with less depletion during 1992 with respect to the non-interactive case (i.e. volcanically unperturbed circulation). This ozone behaviour could be explained with the same arguments adopted for $\mathrm{CH}_{4}$ and $\mathrm{N}_{2} \mathrm{O}$, with the important difference that $\mathrm{O}_{3}$ has its peak concentration in the stratosphere, so that a reinforcement of the residual circulation during 1991/92 ends up accumulating more ozone at the tropopause level in the $100-300 \mathrm{hPa}$ region, where the chemical lifetime is longer than in the lower stratosphere (Fig. 15).

The calculated ozone profile change shows a well-defined tropical decrease at about $25 \mathrm{~km}$ altitude (mostly produced by the additional upwelling) and a layer of ozone increase in the tropopause region (due to the mid- to high-latitude downwelling branch of the perturbative residual circulation). The increase in the tropical upper troposphere is rather large in percent but small in absolute units (about 5-10 ppbv), and is mostly a consequence of the slightly decreasing vertical gradient of the ozone mixing ratio and of a negative $\mathrm{w}^{*}$ perturbation in this region (see Fig. 6a). The calculated ozone trend is much larger when a realistic 'Pinatubo' chemistry is adopted (Fig. 14a): perturbations of photolysis and heterogeneous chemical rates both concur to this enhanced $\mathrm{O}_{3}$ depletion (Pitari and Rizi, 1993). It is interesting to note that the 1992 difference between the fully interactive case and the experiment with no aerosol radiative feedback on circulation is significantly larger with respect to the case where Pinatubo 


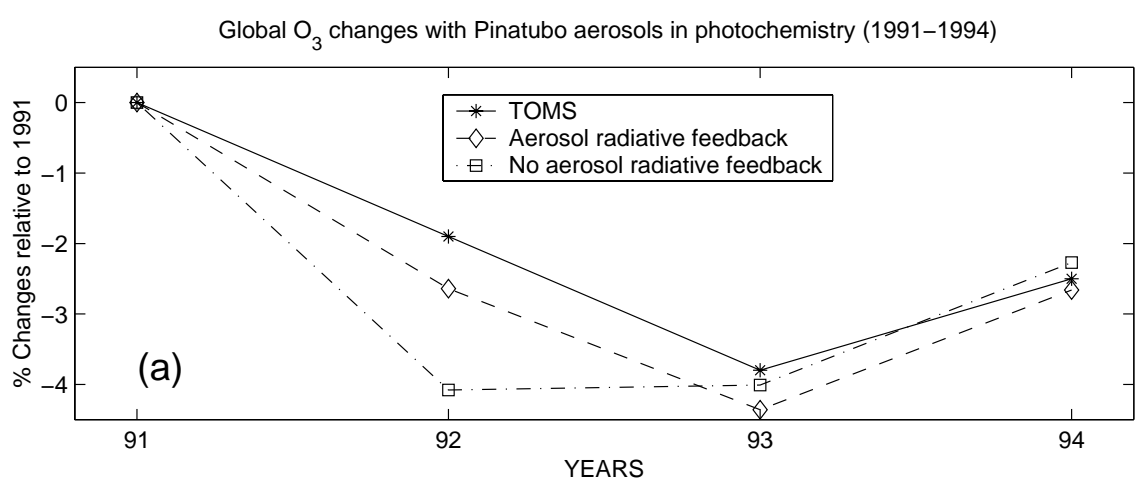

Global $\mathrm{O}_{3}$ changes with background aerosols in photochemistry (1991-1994)

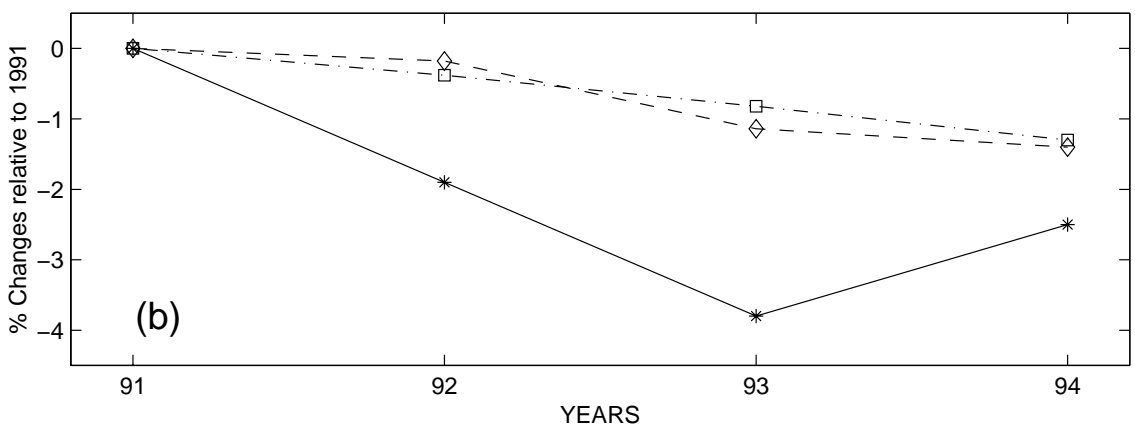

Fig. 14. Global ozone changes relative to $1991(\%)$. Top panel (a) refers to 'I' and 'RNI' simulations using the interactively calculated aerosol distribution in photochemical terms; bottom panel (b) refers to 'CNI' and 'NI' simulations using the 1990 background aerosol distribution in photochemistry (see text for details on the experiments). Solid line is for TOMS measurements (WMO, 1999), dashed line for the radiatively interactive cases ('I' in panel (a) and 'CNI' in panel (b)), and dashed-dotted lines for the radiatively non-interactive cases ('RNI' in (a) and 'NI' in (b)).

aerosols do not interact with photochemistry (Fig. 14b): the reason is that the radiatively perturbed circulation upsets the aerosol distribution itself with a feedback on the chemical depletion efficiency. In particular (see discussion relative to Fig. 7), the additional aerosol heating helps to increase the tropical confinement of the particle slowing down the isentropic poleward motion in the $400-500 \mathrm{~K}$ layer. This means that in the fully interactive experiment less particles are moved toward mid- to high-latitudes during the spring of 1992, thus decreasing the lower stratospheric efficiency of the $\mathrm{N}_{2} \mathrm{O}_{5}$ hydrolysis and the associated additional ozone depletion. An important conclusion of this study is that a coupling of photochemical and dynamical perturbations is necessary to correctly understand the observed features of the post-Pinatubo ozone depletion: photochemistry alone cannot fully explain the $2 \%$ global ozone decline during 1993 with respect to 1992 .

\section{Summary and Conclusions}

A climate-chemistry coupled model has been used to study the short-term climatic impact of the 1991 eruption of Mt. Pinatubo, focusing on the associated changes in the atmospheric general circulation and the related effects on the distribution of long-lived atmospheric tracers and ozone. Despite its coarse resolution and the simplicity of its dynamical scheme, the CCM used in this study presents some interesting features that are particularly relevant to the aim of this study. Not only radiative and photochemical codes interact with dynamics (which is typical of CCMs), but also a microphysical module for aerosol formation and growth extending to both troposphere and stratosphere. The processes of gas-particle interaction are implemented in the model, so that the evolution of the Pinatubo aerosol cloud can be realistically treated: volcanic aerosol formation is initialized by the $\mathrm{SO}_{2}$ injection in the stratosphere followed by oxidation into $\mathrm{H}_{2} \mathrm{SO}_{4}$. The latter process is driven by the abundance of $\mathrm{OH}$ predicted interactively in the chemical module. The model is validated in terms of predicted aerosol optical depth and dynamical anomalies, such as temperature, geopotential height and residual circulation. A discussion is made regarding the similarities with the dynamical regime of the easterly phase of the equatorial wind quasi-biennial oscillation. It is shown that the dynamical perturbation is twofold: (a) the stratospheric mean meridional circulation is affected by local aerosol radiative heating (mostly located in the tropical lower stratosphere); (b) the planetary wave propagation in the mid-to high-latitude lower stratosphere is altered as a consequence of the decreasing atmospheric stability associated to the climatic perturbation. The final step of this study is an attempt to correlate the calculated dynamical anomalies with the observed trends of greenhouse gases (in particular 


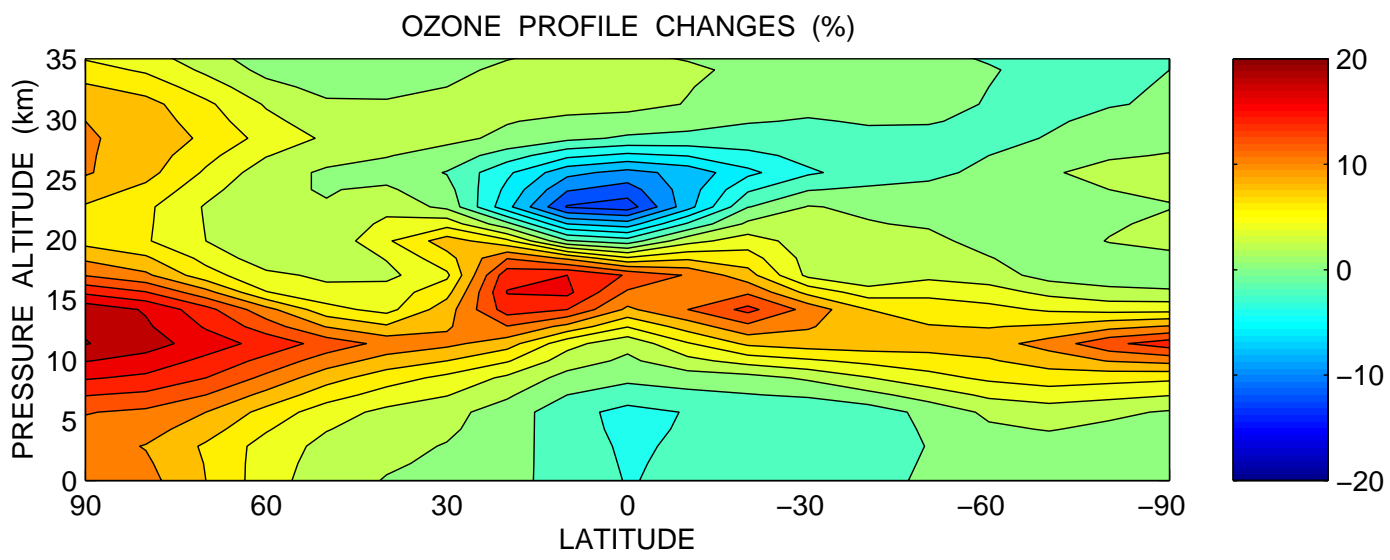

Fig. 15. Calculated ozone profile changes (\%) averaged over July 1991 through June 1992 and due to circulation changes forced by the volcanic aerosols (experiment 'I-RNI'). Contour line spacing is $2 \%$.

$$
\mathrm{CH}_{4}, \mathrm{~N}_{2} \mathrm{O} \text { and } \mathrm{O}_{3} \text { ). }
$$

Major findings of this study are that the radiatively forced changes of the stratospheric circulation during the first two years after the eruption may, to a large extent, explain the observed trend decline of long-lived greenhouse gases $\left(\mathrm{CH}_{4}\right.$ and $\mathrm{N}_{2} \mathrm{O}$, in particular) and may also help explain why simple photochemical studies of the ozone trends generally fail in reproducing the satellite observed features of the ozone depletion. In both cases we conclude that an increase of the mid- to high-latitude downward flux at the tropopause is the key factor for explaining the behaviour of these atmospheric tracers during 1991/92.

Following the suggestion of Schauffler and Daniel (1994), that a decline in the observed $\mathrm{CH}_{4}$ and $\mathrm{N}_{2} \mathrm{O}$ trends could result from a higher degree of exchange between the stratosphere and the troposphere, we have shown that the stratospheric circulation anomalies radiatively forced by the Pinatubo aerosols could indeed increase the mid-latitude stratosphere-troposphere flux of atmospheric tracers. In this regard, not only the extratropical additional downwelling of the mean meridional circulation is important, but also the enhancement in wave activity. It has been shown that aerosol forced stratospheric circulation changes during 1991/92 are responsible for an average tropopause mixing ratio change compatible with the observed trend decline of methane. The observed inter-hemispheric difference (much larger trend decline in the Northern Hemisphere than in the Southern) is consistent with the calculated anomalies of the residual circulation, that are more pronounced in the $\mathrm{NH}$ winter-spring months of 1991/92, as a result of the increased planetary wave activity.

A similar mechanisms also applies to ozone: in this case the largest tracer mixing ratios are located in the stratosphere, so that the reinforcement of the residual circulation during 1991/92 has the effect of moving more ozone towards and below the tropopause, where its chemical lifetime is longer. The overall result is a mitigation of the lower stratospheric photochemical $\mathrm{O}_{3}$ depletion during 1992, so that the largest global impact of Pinatubo aerosols on ozone is postponed until 1993, as observed by satellite instruments.

A future development of this work will be to check the calculated time-dependent distribution of Pinatubo aerosols with available ground-based and satellite observations: this comparison may possibly allow one to draw more definite conclusions on the dynamical role of volcanic aerosol particles. A further validation can also be made on the gasparticle interaction processes taking place in the early stages of the aerosol cloud formation, looking in particular at the evolution of the sulphur dioxide cloud and taking advantage of high-quality satellite observations of $\mathrm{SO}_{2}$ column (TOMS) and vertical profiles (MLS).

Acknowledgements. This work was funded by the EU programme PARTS (EVK2-CT2001-00112).

\section{References}

Angell, J. K. and Korshover, J.: Surface temperature changes following six major volcanic episodes between 1780 and 1980, J. Climate and Appl. Meteorol., 24, 2031-2048, 1985.

Bekki, S., Pyle, J. A., Zhong, W., Toumi, R., Haigh, J. D., and Pyle, D. M.: The role of microphysical and chemical processes in prolonging the climate forcing of the Toba eruption, Geophys. Res .Lett., 23, 2669-2672, 1996.

Bluth, G. J. S., Doiron, S. D., Schnetzler, C. C., Krueger, A. J., and Walter, L. S.: Global tracking of the $\mathrm{SO}_{2}$ clouds from the June, 1991 Mount Pinatubo eruptions, Geophys. Res .Lett., 19, 151-154, 1992.

Brasseur, G. and Solomon, S.: Aeronomy of the middle atmosphere, D. Reidel Ed., 1984.

Carey, S. N. and Sigurdsson, H.: Influence of particle aggregation on deposition of distal Tephra from the May 18, 1980, eruption mount St. Helens volcano, J. Geophys. Res., 87, 7061-7072, 1982.

Dlugokencky, E. J., Masarie, K. A., Lang, P. M., Tans, P. P., Steele, L. P., and Nisbet, E. G.: A dramatic decrease in the growth rate of atmospheric methane in the northern hemisphere during 1992, Geophys. Res. Lett., 21, 45-48, 1994. 
Fahey, D. W. et al.: In-situ measurements constraining the role of sulphate aerosols in mid-latitude ozone depletion, Nature, 363, 509-514, 1993.

Fairlie, T. D. A.: Three-dimensional transport simulations of the dispersal of volcanic aerosol from Mount Pinatubo, Q. J. R. Meteorol. Soc., 121, 1943-1980, 1995.

Forster, P. M. and Shine, K. P.: Radiative forcing and temperature trends from stratospheric ozone changes, J. Geophys. Res., 102, 10 841-10 855, 1997.

Grant, W. B., Browell, E. V., Long, C. S., Stowe, L. L., Grainger, R., and Lambert, A.: Use of volcanic aerosols to study the tropical stratospheric reservoir, J. Geophys. Res., 101, 3973-3988, 1996.

Hansen, J. E., Lacis, A., Ruedy, R., and Sato, M.: Potential climate impact of Mount Pinatubo eruption, Geophys. Res. Lett., 19, 215-218, 1992.

Hansen, J. E. et al.: Forcings and chaos in interannual to decadal climate change, J. Geophys. Res., 102, 25 679-25 720, 1997.

Herzog, M., Graf, H.-F., Textor, C.: The effect of phase changes of water on the development of volcanic plumes, J. Volcanol. Geotherm. Res., 87, 55-74, 1999.

Hobbs, P. V., Radket, L. F., Eltgrot, W., and Hegg, D. A.: Airborne studies of the emissions from the volcanic eruptions of Mt. St. Helens, Science, 211, 816-818, 1981.

Hofmann, D. J. and Rosen, J. M.: Sulfuric acid droplet formation and growth in the stratosphere after the 1982 eruption of El Chichón, Science, 222, 325-327, 1983.

Holton, J. R.: On the global exchange of mass between the stratosphere and troposphere, J. Atmos. Sci., 47, 392-395, 1990.

Holton, J. R. and Tan, H.-C.: The influence of the equatorial quasibiennial oscillation on the global circulation at $50 \mathrm{mb}$, J. Atmos. Sci., 37, 2200-2208, 1980.

IPCC: Climate change 1994: Radiative forcing of climate change, J. T. Houghton et al. Eds., Cambridge University Press, Cambridge, UK, 131-162, 1994.

IPCC: Special report on aviation and the global atmosphere, J. E. Penner et al. Eds., Cambridge University Press, Cambridge, UK, 1999.

Jones, P. D.: Recent warming in the global temperature series, Geophys. Res. Lett., 21, 1149-1152, 1994.

JPL: Chemical kinetics and photochemical data for use in stratospheric modeling, JPL publ. 97-4, 1997.

Kinne, S., Toon, O. B., and Prather, M. J.: Buffering of stratospheric circulation by changing amounts of tropical ozone: A Pinatubo case study, Geophys. Res. Lett., 19, 1927-1930, 1992.

Kirchner, I., Stenchikov, G. L., Graf, H.-F., Robock, A., and Antuna, J. C.: Climate model simulation of winter warming and summer cooling following the 1991 Mount Pinatubo volcanic eruption, J. Geophys. Res., 104, 19 039-19055, 1999.

Kuhlbarsch, T. and Naujokat, B.: Klimabericht zum Juni, August und September und Oktober 1991, Beilage Berliner Wetterkarte, KNH VI/91, VIII/91, IX/91, X/91, 1991.

Labitzke, K. and McCormick, M.P.: Stratospheric temperature increases due to Pinatubo aerosols, Geophys. Res. Lett., 19, $207-$ $210,1992$.

Lacis, A., Hansen, J. E., and Sato, M.: Climate forcing by stratospheric aerosols, Geophys. Res. Lett., 19, 1607-1610, 1992.

Lamb, H. H.: Volcanic dust in the atmosphere; with a chronology and assessment of its meteorological significance, Philos. Trans. R. Soc. London, Ser. A, 266, 425-533, 1970.

Lambert, A., Grainger, R. G., Remedios, J. J., Rodgers, C. D., Corney, M., and Taylor, F. W.: Measurements of the evolution of the Mt. Pinatubo aerosol cloud by ISAM, Geophys. Res. Lett., 20,
1287-1290, 1993.

Long, C. S. and Stowe, L. L.: Using the NOAA/AVHRR to study stratospheric aerosol optical thickness following the Mt. Pinatubo eruption, Geophys. Res. Lett., 21, 2215-2218, 1994.

Mancini, E., Visconti, G., Pitari, G., and Verdecchia, M.: An estimate of the Antarctic ozone modulation by the QBO, Geophys. Res. Lett., 18, 175-178, 1991.

McCormick, M. P. and Veiga, R. E.: SAGE II measurements of early Pinatubo aerosols, Geophys. Res. Lett., 19, 155-158, 1992.

McCormick, M. P., Thomason, L. W., and Trepte, C. R.: Atmospheric effects of the Mt. Pinatubo eruption, Nature, 373, 399404, 1995.

McPeters, R. D., Hollandsworth, S. M., Flynn, L. E., Herman, J. R., and Seftor, C. J.: Long-term ozone trends derived from the 16-year combined Nimbus 7/Meteor 3 TOM Version 7 record, Geophys. Res. Lett., 23, 3699-3702, 1996.

Müller, J.-F. and Brasseur, G.: A three-dimensional transport model of the global troposphere, J. Geophys. Res., 100, 16445-16490, 1995.

NASA: The atmospheric effects of stratospheric aircraft: A first program report, M. J. Prater et al. Eds., NASA Ref. Publ. 1272, 64-91, 1992.

NASA: Models and measurements intercomparison II, J. Park et al. Eds., NASA/TM-1999-209554x, 1999.

Newhall, G. G. and Self, S.: The volcanic explosivity index (VEI): An estimate of explosive magnitude of historic eruptions, J. Geophys. Res., 87, 1231-1238, 1982.

Oberbeck, V. R. et al.: Effect of the eruption of El Chichón on stratospheric aerosol size and composition, Geophys. Res. Lett., 10, 1021-1024, 1983.

Oberhuber, J. M., Herzog, M., Graf, H.-F., and Schwanke, K.: Volcanic plume simulation on large scale, J. Volcanol. Geotherm. Res., 87, 29-53, 1999.

Pinto, J. P., Turco, R. P., and Toon, O. B.: Self-limiting physical and chemical effects in volcanic eruption clouds, J. Geophys. Res., 94, 11 165-11 174, 1989.

Pitari, G.: A numerical study of the possible perturbation of stratospheric dynamics due to Pinatubo aerosols: Implications for tracer transport, J. Atmos. Sci., 50, 2443-2461, 1993.

Pitari, G. and Mancini, E.: Climatic impact of future supersonic aircraft: role of water vapour and ozone feedback on circulation, Phys. Chem. Earth, 26C, 571-576, 2001.

Pitari, G. and Rizi, V.: An estimate of the chemical and radiative perturbation of stratospheric ozone following the eruption of Mt. Pinatubo, J. Atmos. Sci., 50, 3260-3276, 1993.

Pitari, G., Palermi, S., Visconti, G., and Prinn, R. G.: Ozone response to a $\mathrm{CO}_{2}$ doubling: Results from a stratospheric circulation model with heterogeneous chemistry, J. Geophys. Res., 97, 5953-5962, 1992.

Pitari, G., Rizi,V. Ricciardulli,L. and Visconti,G. : High-speed civil transport impact: Role of sulfate, nitric acid trihydrate, and ice aerosol studied with a two-dimensional model including aerosol physics, J. Geophys. Res., 98, 23 141-23 164, 1993.

Pitari, G., Grassi, B., and Visconti, G.: Results of a chemicaltransport model with interactive aerosol microphysics, R. D. Bojkov and G. Visconti Eds., XVIII O 3 Symp. Proc., 759-762, 1997.

Prather, M. J.: Catastrophic loss of stratospheric ozone in dense volcanic clouds, J. Geophys. Res., 97, 10 187-10 191, 1992.

Rampino, M. R. and Self, S.: Sulfur rich volcanic eruptions and stratospheric aerosols, Nature, 307, 344-345, 1984.

Read, W. G., Froidevaux, L., and Waters, J. W.: Microwave 
limb sounder measurements of stratospheric $\mathrm{SO} 2$ from the Mt. Pinatubo volcano, Geophys. Res. Lett., 20, 1299-1302, 1993.

Ricciardulli, L., Pitari, G., and Visconti, G.: Two-dimensional modeling of the time evolution of the Pinatubo aerosol cloud, NATOASI Series, 42, Fiocco et al. Eds., Springer, 71-79, 1996.

Robock, A. and Free, M. P.: Ice cores as an index of global volcanism from 1850 to the present, J. Geophys. Res., 100, 11549 $11567,1995$.

Russel, P. B. et al.: Global to microscale evolution of the Pinatubo volcanic aerosol, derived from diverse measurements and analyses, J. Geophys. Res., 101, 18 745-18 763, 1996.

Schauffler, S. M. and Daniel, J. S.: On the effects of stratospheric circulation changes on trace gas trends, J. Geophys. Res., 99, $25747,1994$.

Schoeberl, M. R., Bhartia, P. K., and Hilsenrath, E.: Tropical ozone loss following the eruption of Mt. Pinatubo, Geophys. Res. Lett., 20, 29-32, 1993.

Simkin, T. and Siebert, L.: Volcanoes of the World, Second Ed., Geoscience Press, Tucson, Az., pp.349, 1994.

Solomon, S., Portmann, R. W., Garcia, R. R., Thomason, L. W., Poole, L. R., and McCormick, M. P.: The role of aerosol variations in anthropogenic ozone depletion at northern midlatitudes, J. Geophys. Res., 101, 6713-6727, 1996.

Stenchikov, G. L., Kirchner, I., Robock, A., Graf, H.-F., Antuna, J. C., Grainger, R., Lambert, A., and Thomason, L.: Radiative forcing from the 1991 Mt. Pinatubo volcanic eruption, J. Geophys. Res., 103, 13 837-13 858, 1998.

Stoiber, R. E., Williams, S. N., and Huebert, B.: Annual contribution of sulfur dioxide to the atmosphere by volcanoes, J. Volcanol. Geotherm. Res., 33, 1-8, 1987.

Stowe, L. L., Carey, R. M., and Pellegrino, P. P.: Monitoring the Mt. Pinatubo aerosol layer with NOAA/11 AVHRR data, Geophys. Res. Lett., 19, 159-162, 1992.
Swanson, T. H. et al.: Nitrous oxide and halocarbons division, Climate Monitoring and Diagnostic Laboratory No 21, Summary Report, 1992, edited by J. T. Peterson and R. M. Rosson, pp. 59-75, NOAA ERL, Boulder, 1993.

Textor, C.: Numerical simulation of scavenging processes in explosive volcanic eruption clouds, $\mathrm{Ph}$. D. Thesis Max-Planck-Institut für meteorologie, 1999.

Thomason, L. W., Poole, L. R., and Deshler, T.: A global climatology of stratospheric aerosol surface area density from Stratospheric Aerosol and Gas Experiment II measurements: 1984 1994, Geophys. Res., 102, 8967-8976, 1997.

Timmreck, C., Graf, H.-F., and Kirchner, I.: A one and half year interactive MA/ECHAM4 simulation of Mt. Pinatubo aerosol, J. Geophys. Res., 104, 9337-9359, 1999.

Trepte, C. R. and Hitchman, M. H.: Tropical stratospheric circulation deduced from satellite aerosol data, Nature, 355, 626-628, 1992.

Trepte, C. R., Veiga, R. E., and McCormick, M. P.: The poleward dispersal of Mount Pinatubo volcanic aerosol, J. Geophys. Res., 98, 18 563-18 573, 1993.

Weisenstein, D. K., Yue, G. K., Ko, M. K. W., Sze, N.-D., Rodriguez, J. M., and Scott, C. J.: A two-dimensional model of sulfur species and aerosols, J. Geophys. Res., 102, 13 019-13 035, 1997.

WMO: Scientific assessment of ozone depletion: 1991, Global ozone research and monitoring project, WMO rep. $\sharp 25,1992$.

WMO: Scientific assessment of ozone depletion: 1998, Global ozone research and monitoring project, WMO rep. $\sharp 44,1999$.

Young, R. E., Houben, H., and Toon, O. B.: Radiatively forced dispersion of the Mt. Pinatubo volcanic cloud and induced temperature perturbations in the stratosphere during the first few months following the eruption, Geophys. Res. Lett., 21, 369-372, 1994. 